\title{
Characterization of the W7-X scrape-off layer using reciprocating probes Paper
}

Killer, Carsten; Grulke, Olaf; Drews, Philipp; Gao, Yu; Jakubowski, Marcin; Knieps, Alexander; Nicolai, Dirk; Niemann, Holger; Sitjes, Aleix Puig; Satheeswaran, Guruparan

Total number of authors:

11

Published in:

Nuclear Fusion

Link to article, DOI:

10.1088/1741-4326/ab2272

Publication date:

2019

Document Version

Early version, also known as pre-print

Link back to DTU Orbit

Citation (APA):

Killer, C., Grulke, O., Drews, P., Gao, Y., Jakubowski, M., Knieps, A., Nicolai, D., Niemann, H., Sitjes, A. P., Satheeswaran, G., \& W7-X Team (2019). Characterization of the W7-X scrape-off layer using reciprocating probes: Paper. Nuclear Fusion, 59(8), [086013]. https://doi.org/10.1088/1741-4326/ab2272

\section{General rights}

Copyright and moral rights for the publications made accessible in the public portal are retained by the authors and/or other copyright owners and it is a condition of accessing publications that users recognise and abide by the legal requirements associated with these rights.

- Users may download and print one copy of any publication from the public portal for the purpose of private study or research.

- You may not further distribute the material or use it for any profit-making activity or commercial gain

- You may freely distribute the URL identifying the publication in the public portal 


\title{
Characterization of the W7-X Scrape-Off Layer using reciprocating probes
}

\author{
Carsten Killer $^{1} \ddagger$, Olaf Grulke ${ }^{1,3}$, Philipp Drews ${ }^{2}$, Yu Gao $^{2}$ \\ Marcin Jakubowski ${ }^{1}$, Alexander Knieps ${ }^{2}$, Dirk Nicolai ${ }^{2}$, \\ Holger Niemann ${ }^{1}$, Aleix Puig Sitjes ${ }^{1}$, Guruparan \\ Satheeswaran $^{2}$, W7-X Team ${ }^{1}$ \\ ${ }^{1}$ Max-Planck-Institut für Plasmaphysik, Greifswald, Germany \\ 2 Forschungszentrum Jülich, IEK-4 Plasmaphysik, Jülich, Germany \\ ${ }^{3}$ Department of Physics, Technical University of Denmark, Lyngby, Denmark
}

\begin{abstract}
.
The W7-X Scrape-Off Layer (SOL) with its characteristic magnetic island chain has been investigated using electric probes mounted on a reciprocating manipulator close to the outboard mid-plane. A survey of the W7-X configuration space shows that the presence and particular topology of magnetic islands significantly affects the SOL profiles of electron temperature, density, electric field and plasma flows. Particularly relevant for divertor operation, very wide SOL heat flux profiles have been observed in some magnetic configurations, which we link to the presence of magnetic islands. In these situations, the islands can feature a local minimum of the plasma potential accompanied by a direction reversal of $E \times B$ driven dynamics measured by probe arrays.
\end{abstract}

Submitted to: Nucl. Fusion

‡ carsten.killer@ipp.mpg.de 


\section{Introduction}

The Wendelstein 7-X (W7-X) stellarator employs the island divertor concept, where heat and particle exhaust to the divertors is controlled through large, low rational magnetic islands at the plasma edge. An island divertor has first been implemented in W7AS $[1,2]$ and is now employed by W7-X [3], which (after a first campaign of limited plasmas 2015/2016 $[4,5])$ concluded its first two divertor operation phases recently $(2017 / 2018)[6]$.

Understanding the effect of the edge magnetic island topology on the Scrape-Off Layer (SOL) profiles, dynamics and transport is fundamental for the assessment of the divertor performance and future improvement of divertor operation scenarios. A key parameter for the SOL characterization is its width, which is determined by the competition between parallel and perpendicular transport in the SOL, and which affects the head load patterns on the divertor. While tokamaks of comparable operation regimes to W7-X feature SOL widths of some $\mathrm{mm}$ [7], the W7$\mathrm{X}$ SOL width can be expected to be larger with a stronger role of perpendicular transport due to the long magnetic connections lengths (typically a few $100 \mathrm{~m}$ ). An additional factor determining the SOL is the energy and particle fuelling across the last closed flux surface (LCFS). It is therefore essential to survey key SOL plasma parameters in both the W7-X magnetic configuration space and in the central plasma parameter space.

An established technique to address these aspects in the SOL is the use of reciprocating electric probes, which can provide profiles of electron temperature, density, plasma potential, plasma flows and in addition offer the possibility to study turbulent fluctuations from which cross-field transport can be estimated, see e.g. Refs. $[8,9,10,11]$. At W7-X, the MultiPurpose Manipulator (MPM) serves as a carrier system for various probe heads [12]. It is installed at the outboard mid-plane and can perform fast reciprocating plunges through the island chain up to the LCFS of the confined plasma. While the MPM was employed for a wide variety of applications (such as magnetic probes, material studies, impurity injection, gas fueling and more), we here focus on electric probe measurements which provide profiles of key plasma parameters: electron temperature, density and electric field are determined from triple probes and swept Langmuir probes, while plasma turbulence characteristics are inferred from spatially distributed arrays of probes operating in floating potential or ion saturation current mode.

This paper is structured as follows: After introducing the MPM and the magnetic configuration space in section 2, the IPP-FLUC1 probe head and probe analysis techniques are presented in section 3. In section 4, SOL plasma profiles in the W7-X magnetic configuration space are presented for different rotational transform values and both limiter and island divertor configurations. Section 5 is devoted to SOL profiles in the magnetic standard configurations and also gives a first insight into the dynamics of the island plasma profiles during a plasma program. The paper concludes with a summary in section 6 .

\section{The Multi-Purpose Manipulator (MPM)}

The Multi-Purpose Manipulator (MPM) [12] serves as a versatile carrier system for a multitude of probe heads ranging from electric and magnetic probes of different kinds to plasma-wall interaction probes to plasma fuelling and impurity generation. It is mounted at the outboard mid-plane of W7-X at a toroidal angle of $\phi_{\text {tor }}=200.8^{\circ}$. The MPM consists of two stacked linear drives which are actuated by servo motors: The slow linear drive carries the probe head about $2.5 \mathrm{~m}$ from the exchange chamber outside the cryostat to a "parking position" close to the plasma vessel wall. From there, a second, fast linear drive allows fast plunges into the plasma with a maximum depth of $350 \mathrm{~mm}$ at a maximum acceleration of $30 \mathrm{~m} / \mathrm{s}^{2}$ [12, 23]. An overview of all MPM probe heads used since W7-X went into operation is given in Table 1 with references where available. This manuscript focuses on the IPPFLUC1 probe head and uses a few results from FZJCOMB2.

The path of the MPM with respect to the magnetic topology is indicated in the Poincare plots in Figure 1 for three representative magnetic configurations representing the accessible range of the edge rotational transform $\iota_{\text {edge }}$ of W7-X from $\iota_{\text {edge }}=5 / 6$ (low iota) over $\iota_{\text {edge }}=5 / 5$ (standard) to $\iota_{\text {edge }}=5 / 4$ (high iota). In the magnetic standard configuration (Figure $1 \mathrm{a})$ ), the MPM crosses the $5 / 5$ island chain about $10 \mathrm{~cm}$ above the island's O-point. The connection length along the MPM path is shown in Figure 2 a) for different magnetic configurations and in Figure 
Table 1. List of MPM probe heads

\begin{tabular}{lll} 
Probe head & Operation Phase & Description \\
\hline FZJ-COMB1 $[13,14]$ & OP1.1 & 9 Electric probes, magnetic pick-up probe \\
FZJ-COMB2 $[15,16]$ & OP1.2a/b & 9 Electric probes, magnetic pick-up probe, ion sensitive probe, \\
& & material exposition, gas pipe \\
IPP-FLUC1 & OP1.2a/b & 28 Electric probes (poloidal array, parallel + poloidal Mach probe) \\
FZJ-MACH1 $[17]$ & OP1.2a & Polar (Gundestrup) + radial Mach probe array $(28$ electrodes) \\
FZJ-RFA1 $[18]$ & OP1.2a & 6 retarding field analyzers, 2 electric probe pins \\
FZJ-GAS1 & OP1.2a & 4 electric probe pins, gas pipe \\
FZJ-GAS2 & OP1.2b & 4 electric probe pins, piezo valve for gas injection \\
FZJ-MACH2 & OP1.2b & Polar (Gundestrup) + radial Mach probe array $(28$ electrodes) \\
FZJ-RFA2 & OP1.2b & 6 retarding field analyzers, 4 electric probe pins, gas pipe \\
RFX-HRP1 $[19]$ & OP1.2b & 3 magnetic pick-up probes, 8 electric probe pins, 3 Mach probes \\
NIFS-FILD1 $[20]$ & OP1.2b & 8 Faraday films for fast ion loss detection \\
FZJ-MAT1 & OP1.2a & 8 samples for material exposition \\
FZJ-MAT2 & OP1.2b & 18 samples for material exposition \\
IPP-LBO1 $[21]$ & OP1.2a/b & Holds four coated glass targets for laser ablation \\
PPPL-PMPI1 $[22]$ & OP1.2b & Horizontal powder flinger for boron impurity injection
\end{tabular}
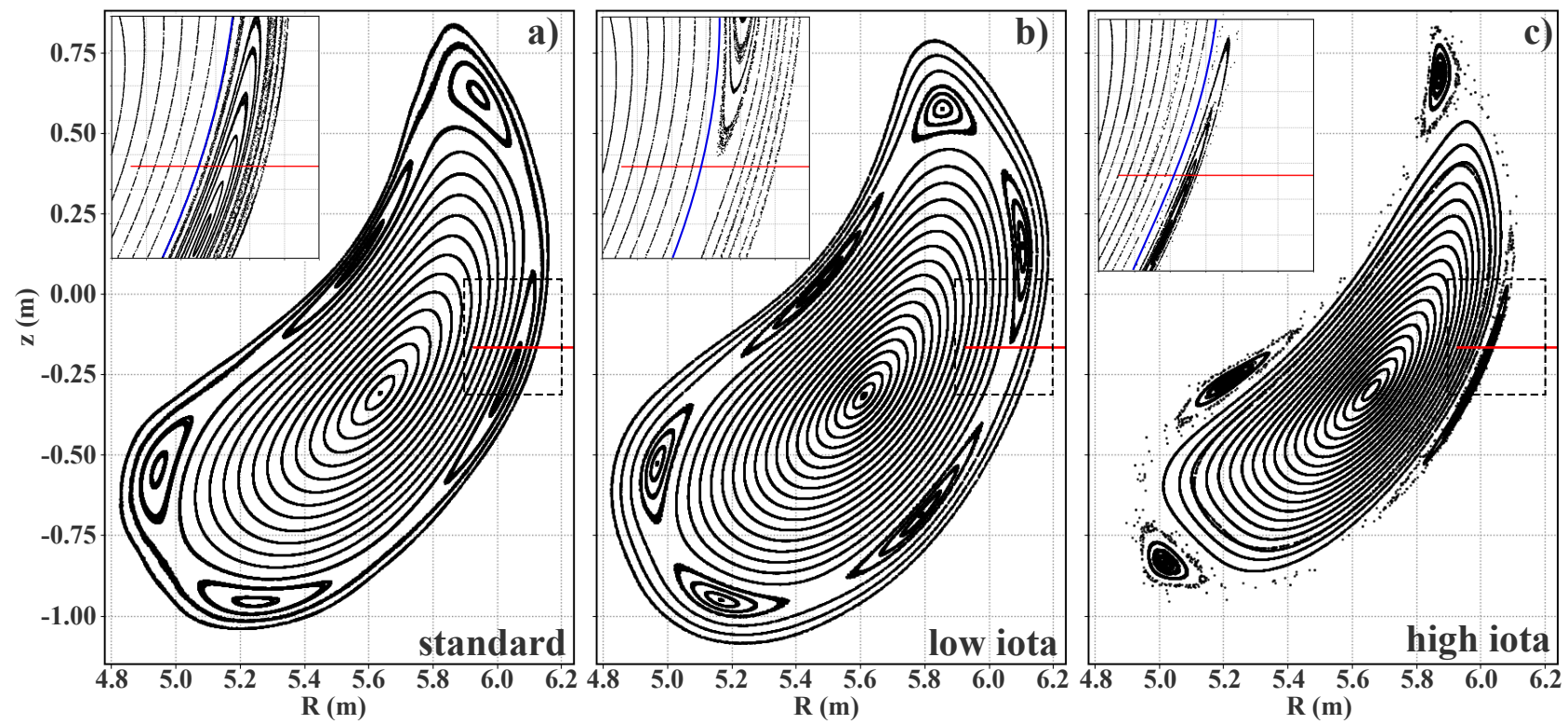

Figure 1. Poincare plots of the MPM plasma cross section of W7-X for a) Standard configuration (EJM) with $5 / 5$ individual islands, b) low iota configuration (DBM) with a $5 / 6$ island chain, c) high iota configuration (FTM) with a 5/4 island chain. The accessible probe plunge range is indicated as the solid red line. The insets provide close-up views of the probe path region (indicated by the dashed rectangles) and include an estimate of the last closed flux surface represented by a blue line.

2 b) in the vicinity of the MPM in the standard configuration. Following the connection length profile along the MPM path in this configuration, the role of the magnetic island is illustrated by the steep increase of the connection length around $R=6.07 \mathrm{~m}$ and a complex pattern of different connection lengths inside the island. The field lines starting in the vicinity of the MPM are intersected mostly by three out of the 10 divertor modules as indicated in Figure 2 c). As an interesting note, the various patches of slightly different hues in the island region in Figure $2 \mathrm{~b}$ ) are all intersected by either the upper divertor in module 1 or the lower divertor in module 3 . However, the number of toroidal orbits around the entire machine (major radius $R \sim 5.5 \mathrm{~m}$ ) until the field line hits the target varies, resulting the in the connection length distribution being in Figure $2 \mathrm{~b}$ ) being more complex than the divertor target map in Figure $2 \mathrm{c}$ ). We finally note that the island topology and distribution of connection lengths is very sensitive to even slight magnetic perturbations, e.g. due to toroidal plasma currents. This issue is, however, outside the scope of 
a)

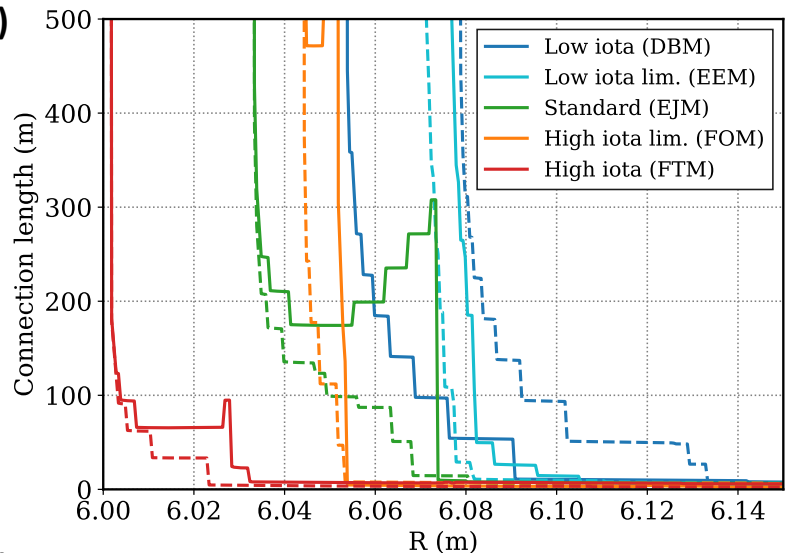

b)

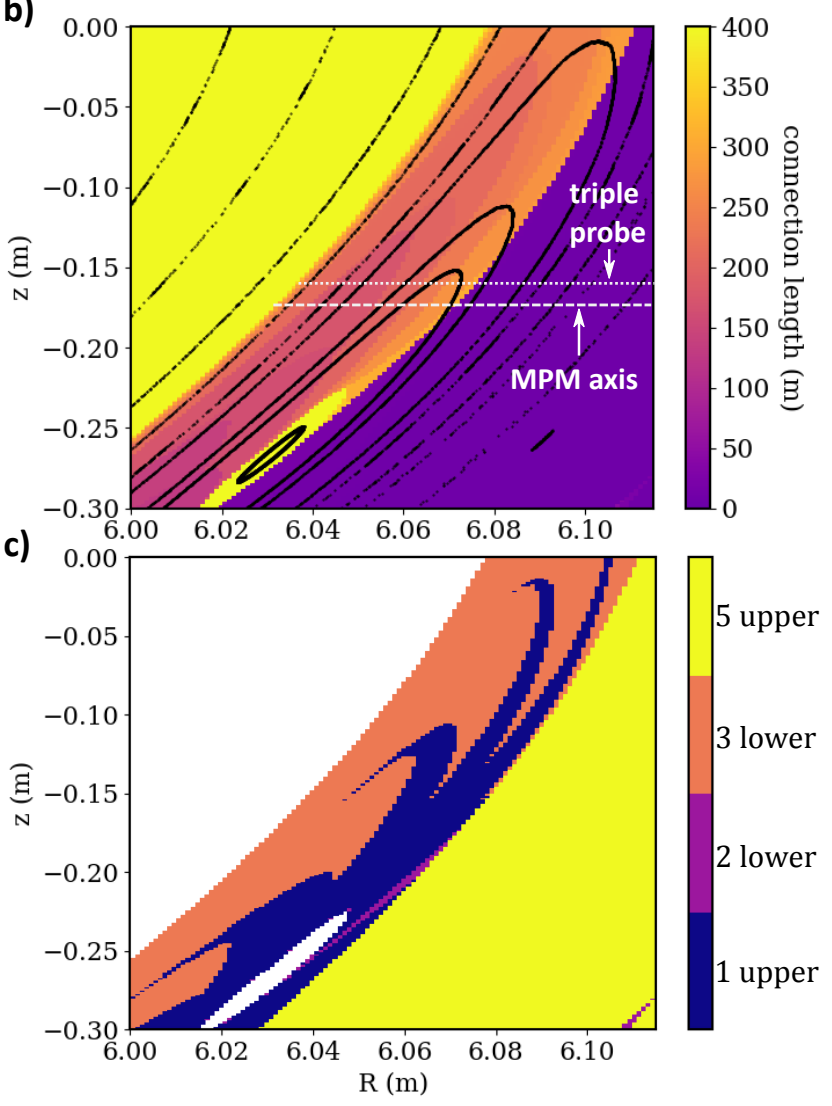

Figure 2. a) Radial profiles of the connection length along the MPM (axis) path in the configurations explored in this paper. The solid lines correspond to the forward direction (along the magnetic field) and the dashed lines to the backwards direction. b) Connection lengths from the region around the MPM in the forward direction of the magnetic field in the standard configuration (EJM). A Poincare plot indicated by black dots is superposed. In addition, the MPM (axis) path (dashed line) and the path of the triple probe on the IPP-FLUC1 probe head (dotted line) is shown. c) Map of divertor targets intersecting the field lines in the same region of interest as in b).

this paper and is discussed elsewhere [15].

In the low iota configuration (Figure $1 \mathrm{~b}$ )), the MPM path is located slightly above the X-point. In the high iota configuration (Figure $1 \mathrm{c}$ )), in contrast, the
Table 2. W7-X magnetic configurations relevant to this paper, sorted by edge rotational transform.

\begin{tabular}{llll} 
Configuration & $\iota_{\text {edge }}$ & Resonance & Label \\
\hline Low Iota & 0.83 & $5 / 6$ & DBM \\
Low Iota Limiter & 0.93 & none & EEM \\
Standard & 1 & $5 / 5$ & EJM \\
High Iota Limiter & 1.1 & none & FOM \\
High Iota & 1.25 & $5 / 4$ & FTM
\end{tabular}

MPM again crosses slightly above the O-point of a very narrowly compressed island. The connection length profiles in Figure 2 also illustrate the effect of different magnetic configurations on the position of the last closed flux surface, which we estimate at the radial position where the connection length reaches infinity. An overview of the magnetic configurations addressed in this paper is given in Table 2 which also provides short labels for the configurations that will be used in the following sections.

\section{Probe head IPP-FLUC1}

The IPP-FLUC1 probe head, shown in Fig. 3, is dedicated to the measurement of SOL profiles and fluctuations in W7-X. The probe head contains a poloidal array of 22 pins which are arranged in two columns with alternating poloidal positions. The cylindrical pins are made of molybdenum, have a diameter of $2 \mathrm{~mm}$ and protrude from the probe head by $2 \mathrm{~mm}$. The poloidal separation between two adjacent pins within one column is $5 \mathrm{~mm}$ while the base length of the entire array is $50 \mathrm{~mm}$, resulting in a wave number resolution of $0.6 \mathrm{~cm}^{-1}<k_{\mathrm{pol}}<6 \mathrm{~cm}^{-1}$. Two further pins are located at the bottom of the probe where they protrude downwards at two different radially recessed positions. Above the poloidal array, a Mach probe following the design of Smick et al. is located, which can provide parallel and poloidal Mach numbers simultaneously $[24,25]$.

The probe head body is entirely made from high purity grade boron nitride which can withstand high temperatures $\left(2000^{\circ} \mathrm{C}\right)$ while offering high heat conductivity, low thermal expansion, and high electric resistivity [26]. To fit the 3D geometry of the W7$\mathrm{X}$ SOL, the probe head is $3 \mathrm{D}$ shaped to resemble the inclination of the magnetic surfaces (averaged over major magnetic configurations) and the magnetic pitch angle at the position of the MPM. The stains on the (initially white) boron nitride after plasma operation indicate that the shaping worked well in general, although the plasma impression in the side view shows a deviation of up to $3^{\circ}$ with respect to the angle against the vertical direction (arrows in Figure 3).

The 28 electric pins and two additional thermocouples 


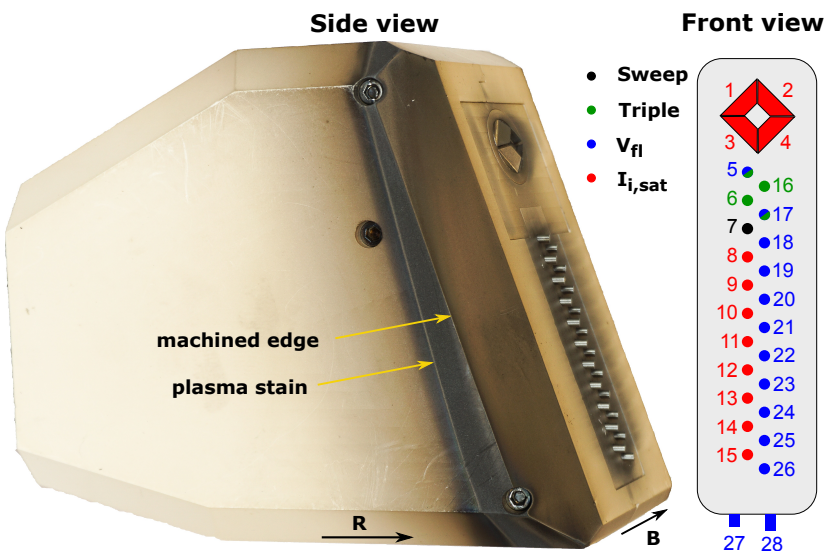

Figure 3. Probe head IPP-FLUC1 (side view) with schematic pin layout as seen from the plasma (front view).

for operation safety monitoring are connected to the MPM's 32 channel interface [12]. A typical operation design of the probe head is shown in the scheme in Fig. 3: The two rows of the poloidal array are mostly used for floating potential and ion saturation current measurement, respectively. In addition, a triple probe setup [27] and a classic swept Langmuir probe [28] for $n_{\mathrm{e}}, T_{\mathrm{e}}$ profile measurements are included. For the Mach probe, all four electrodes are individually operated in ion saturation mode. The biasing for all ion saturation and triple probe operation is provided by supercapacitor modules which are inherently potential-free and can provide steady large currents while providing bias voltages up to $320 \mathrm{~V}$ [12]. Such voltages are required for swept Langmuir probe operation and ion saturation current collection since typical floating potentials in our measurements are in the range of $100 \mathrm{~V}$ to $+200 \mathrm{~V}$, see e.g. Figure 11.

The Mach probe following the design of Smick and LaBombard [24, 25] resembles a four-sided pyramid with an inclination of $45^{\circ}$ where each face of the pyramid is an individual electrode collecting ion saturation currents. From these currents, a 2D vector flow field is determined by solving equation 1 in a least squares sense. Since the orientation of the Mach probe array is such that the vertices of the pyramid point in the parallel and poloidal magnetic direction, the velocity components can be attributed to the parallel and poloidal Mach numbers $M_{\|}$and $M_{\perp}$. The equation system providing the Mach numbers as well as the unobstructed probe current $j_{0}$ can therefore be written as:

$\ln \left(j_{\mathrm{NW}} / j_{0}\right)=M_{\|}+M_{\text {pol }}-1$

$\ln \left(j_{\mathrm{SW}} / j_{0}\right)=M_{\|}-M_{\text {pol }}-1$

$\ln \left(j_{\mathrm{NE}} / j_{0}\right)=-M_{\|}+M_{\text {pol }}-1$

$\ln \left(j_{\mathrm{SE}} / j_{0}\right)=-M_{\|}-M_{\text {pol }}-1$

where the notation of individual probes refers to
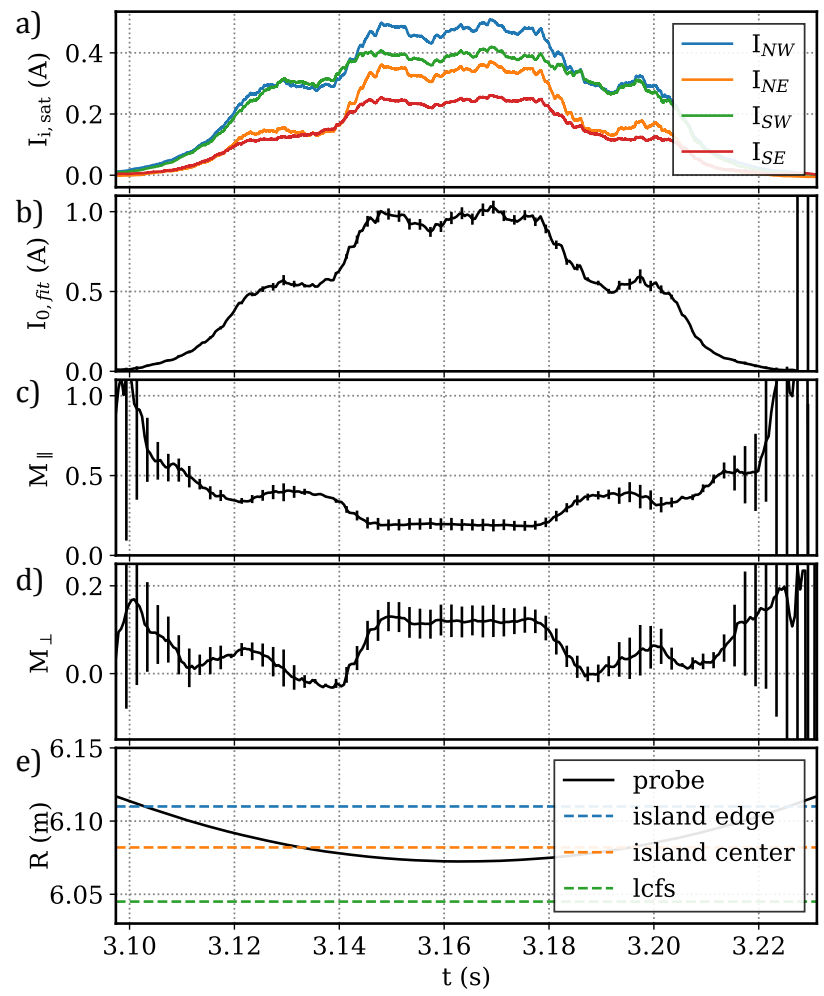

Figure 4. Principle of Mach probe operation after [24]. a) Time traces of ion saturation currents measured by the four individual electrodes during a typical fast plunge into the magnetic island (signals are smoothed for clarity). From equation 1 we obtain the unobstructed ion saturation current (b), the parallel Mach number (c) and the perpendicular Mach number (d). The error bars resemble the respective covariance components of the leastsquare fit of equation 1 . For reference, the probe position with respect to the island position and the last closed flux surface is given in e).

directions, with east-west being aligned along the magnetic field (toroidal) and north-south being perpendicular to it on the same flux surface (poloidal). The Mach probe operation is illustrated in Figure 4: The time traces of the individual currents during a plunge into the magnetic island in the standard configuration (EJM) are shown in Fig. 4 a). The initially unknown variables $M_{\|}, M_{p o l}, j_{0}$ obtained by solving equation 1 are shown in Fig. 4 b) - d), while the bottom panel e) depicts the (radial) position of the Mach probe during the plunge. The parallel Mach number is positive (being defined as clockwise plasma flow) during the entire radial plunge which is consistent with connection length considerations and EMC3-Eirene modeling [29]. Following the time traces while the probe moves closer to the LCFS, a significant change of the Mach numbers is seen once the probe crosses the island center. In the outer part of the profile (i.e. $t<3.145 \mathrm{~s}$ ), $M_{\|} \approx 0.3-0.4$ and $M_{\text {pol }} \approx 0$. In the inner part of the island $(3.15 \mathrm{~s}<$ $t<3.18 \mathrm{~s}$ ), in contrast, $M_{\|} \approx 0.2$ while $M_{\text {pol }}$ becomes 

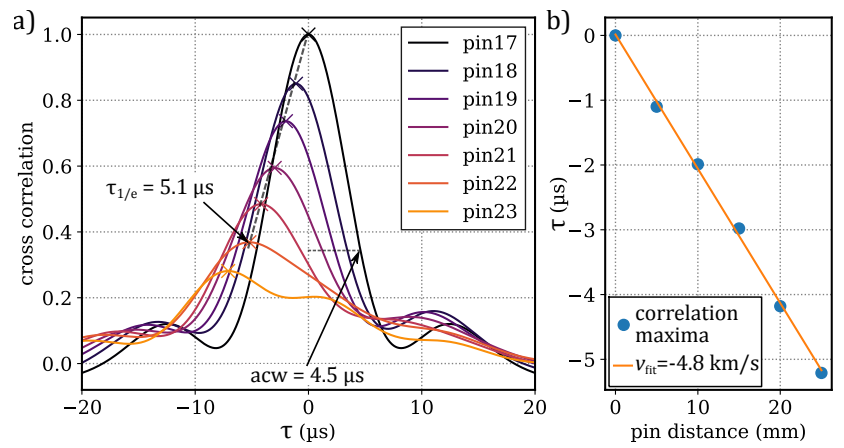

Figure 5. a) Cross correlation between various floating potential pins. b) The propagation velocity is obtained from a linear fit of the cross correlation maxima delay times as a function of the respective pin distances.

significantly larger than zero, up to more than 0.1 . From the definition of the equation system 1 positive $M_{p o l}$ is directed downwards, which would correspond to a negative radial electric field assuming the flow is $E \times B$ driven. While this Mach probe setup provides reliable and physics-wise consistent results (see section 5 ), it should be noted that the relatively simple model (equation 1) assumes that there is no radial plasma flow and requires a good alignment of the Mach probe to the magnetic field. This is especially difficult in the 3D magnetic topology of W7-X where the flux surface shape and magnetic pitch angle can change significantly along the probe path, especially when crossing an island.

The poloidal probe array depicted in Figure 3 offers a wide range of physics investigations since fluctuations of the plasma density (via ion saturation pins) and potential (via floating pins) can be studied with good spatio-temporal resolution. Investigating detailed turbulence characteristics is however beyond the scope of this manuscript and will be addressed in a future publication. Here, we focus on the propagation of fluctuating structures along the poloidal array which we investigate by cross-correlating the data from different probe pins. From the poloidal phase velocity obtained by correlation analysis, the radial electric field can be estimated, assuming that the poloidal dynamics are determined by the poloidal $E \times B$ flow (diamagnetic drift velocities are usually small due to the relatively shallow pressure profiles in the W7-X SOL, see the following sections).

This procedure is illustrated in Figure 5: In a typical plasma in the magnetic standard configuration, the probe took data in the setup presented in Figure 3 while remaining at a constant position just inside the outer edge of the island for several $100 \mathrm{~ms}$. The raw data (taken with $2 \mathrm{MHz}$ ) was first bandpass-filtered in the frequency band $f_{\text {filt }}=5 \ldots 100 \mathrm{kHz}$ in order to remove low frequency $(1-2 \mathrm{kHz})$ coherent modes [30] as well as high frequency electronic noise. Figure 5 a) presents the cross correlation amplitude between seven floating potential pins during a time interval of $100 \mathrm{~ms}$. With increasing distance from the reference pin (pin 17), the cross correlation magnitude decreases while the time delay increases. The life-time of fluctuating structures $\tau_{1 / \mathrm{e}}$ is determined as the delay where the cross correlation maximum drops to the $1 /$ e level and the auto-correlation width (acw) is determined from the width of the auto-correlation function of pin 17 at the $1 /$ e level.

From the delay times of cross correlation maxima plotted with respect to their distances, the poloidal propagation velocity is obtained from a simple linear fit as presented in Figure $5 \mathrm{~b}$ ). As pin 17 is on top of the array, the observed propagation is directed upwards, being consistent with a positive radial electric field $E_{\mathrm{r}}$ in the SOL. With the magnetic field strength of $B=2.3 \mathrm{~T}$ at the MPM position, $E_{\mathrm{r}} \approx 11 \mathrm{kV} / \mathrm{m}$ is estimated, which is consistent with reflectometry results [31].

Finally, triple probe arrangements have been employed to estimate electron temperature, density and floating potential. The triple probe technique is a simple but efficient diagnostic which however has a number of limitations, e.g. inherently assuming Maxwellian distributions and that all three probe pins are subject to the same plasma conditions while not disturbing each others measurement $[27,32,33]$. Regarding the latter argument, the low shear configuration of W7-X is accommodating for triple probes since the pitch angle does not change significantly along the probe path. A systematic cross-comparison and validation of different edge profile diagnostics such as thermal Helium beam spectroscopy, divertor Langmuir probes, Alkali-Metal beam emission spectroscopy, reflectometry, Thomson scattering, and different MPM probe heads with triple and swept Langmuir probes is quite challenging due to the complicated 3D SOL of W7-X and is therefore still under investigation.

The triple probe directly measures the positive potential of a floating double probe arrangement $V_{+}$, the ion saturation current $I_{\mathrm{i} \text {,sat }}$ into the other pin of the double probe, as well as the floating potential from a third pin $V_{\mathrm{fl}}$. From these measurements, we infer the electron temperature $T_{\mathrm{e}}=\left(V_{+}-V_{\mathrm{f}}\right) / \ln 2$, the plasma potential $V_{\mathrm{pl}}=V_{\mathrm{fl}}+2.8 k_{B} T_{\mathrm{e}}$, and the plasma density $n=I_{\mathrm{i}, \mathrm{sat}} /\left(0.49 A_{\mathrm{eff}} e c_{s}\right)$ where $A_{\text {eff }}$ is the effective probe surface area and $c_{s}=\sqrt{k_{B}\left(Z T_{\mathrm{e}}+\gamma T_{\mathrm{i}}\right) / m_{\mathrm{i}}}$ is the speed of sound. The latter contains variables which are not yet well characterized for W7-X, in particular the charge state $Z$ and ion mass $m_{\mathrm{i}}$ which are subject to the impurity content as well as the ion temperature in the SOL. Hence, at a lack of credible estimates for these properties in the still quite new W7-X, we here assume 
an isothermal pure hydrogen plasma $\left(Z=1, m_{\mathrm{i}}=m_{\mathrm{p}}\right.$, $\left.T_{\mathrm{e}}=T_{\mathrm{i}}\right)$ and $\gamma=1$ for simplicity. The effective probe area is simply estimated by the geometric projection to the proud probe pins along the magnetic field as $A_{\text {eff }}=2 l d$ where $l$ and $d$ are the length and diameter of the probe pins, respectively. This assumptions holds well along the entire probe path due to the low magnetic shear of W7-X.

For the sake of visual clarity, results from Triple probe measurements are smoothed using a $200 \mathrm{~Hz}$ lowpassfilter (if not stated otherwise) in the following figures of this manuscript.

\section{SOL plasma profiles in the $\mathrm{W} 7-\mathrm{X}$ magnetic configuration space}

In this section, the role of the magnetic configuration as well as plasma heating power and central density on the SOL profiles is explored. We first investigate limiter configurations without edge magnetic islands since the simpler magnetic topology allows for an easier interpretation of the results. Then, we proceed to the low iota and high iota island divertor configurations. In each figure, various plasma discharges with different central plasma parameters are presented. To avoid overloading the figures, the legends were kept as short as possible, giving the experiment numbers of the experiment day provided in the figure title and the ECRH power as well as the line integrated plasma density $n_{d l}$ in $\mathrm{m}^{-2}$ (dividing the latter by the interferometer chord length of $1.3 \mathrm{~m}$ provides an estimate of the mean plasma density in $\mathrm{m}^{-3}$ ). If not stated otherwise, all experiments were performed in hydrogen with pure ECR heating.

In order to compare the SOL width between different W7-X configurations and to tokamaks, the parallel heat flux profiles to the divertor are estimated as convective fluxes via $q_{\|}=n c_{s} T_{\mathrm{e}}$. Although this approach cannot be used for quantitative analysis and direct comparisons to divertor loads (since it misses e.g. the ion temperature [34], heat transmission coefficients, and does not account for conductive heat transport), it is a widely used measure for tokamaks [35, 7, 36]. There, the $q_{\|}$profiles typically show an exponential decay in the SOL with a characteristic fall-off length $\lambda_{q}$, which is taken as the SOL width:

$\left.q_{\|}(R)=q_{\|, 0} \exp \left(\left(R-R_{0}\right) / \lambda_{q}\right)\right)$

In magnetic configurations operating as island divertor, Poincare plot close-ups of the vicinity of the MPM path are given to illustrate the particular magnetic topology. These Poincare plots were produced using the designed coil set of W7-X. Deviations of the coil geometry due to assembly tolerances and forces are not taken into considerations. Thus, the so obtained vacuum magnetic field is used to illustrate the fundamental mag- netic field geometry and are not being used for detailed quantitative estimates.

Although W7-X is designed for and almost entirely operates in island divertor magnetic configurations, the superconducting coil system can also create configurations where rational islands are moved inwards or outwards such that the SOL does not contain magnetic islands. As a result, nested flux surfaces exist up to the divertor, which therefore acts like limiter. These configurations provide an ideal testbed for understanding the W7-X SOL without the complication of magnetic islands. In the following we focus on two representative limiter configurations: The EEM configuration (Figure 6) is almost identical to the configuration used in the very first W7-X campaign OP1.1 $[13,5]$ with a rotational transform roughly halfway between standard and low iota. The FOM configuration (Figure 7) serves as a counterpart in the high iota space, as it features a rotational transform roughly halfway between standard and high iota.

The EEM configuration (Figure 6) has been operated at comparably low performance: All presented measurements were taken at a heating power of $3.2 \mathrm{MW}$ with line integrated densities $n_{d l}$ around $3 \cdot 10^{19} \mathrm{~m}^{-2}$ (20180829.51) and $2 \cdot 10^{19} \mathrm{~m}^{-2}$ (20180829.52). In both cases, the plasma duration was $8.5 \mathrm{~s}$ with MPM plunges at around $2 \mathrm{~s}$ and $8 \mathrm{~s}$. The temperature and density profiles in Figure 6 show no distinct features and reveal slightly smaller temperatures and higher densities in the case of higher $n_{d l}$. The evolution of the toroidal (bootstrap) current by several kA in between both measurements within one plasma discharge has no significant effect on the profiles. The slightly decreasing density in the course of program 20180829.51 stems from the central plasma density feedback control system which at $2 \mathrm{~s}$ after plasma startup had not yet stabilized the planned density of $3 \cdot 10^{19} \mathrm{~m}^{-2}$. The heat flux profiles resemble exponential shapes with decay lengths of $8-10 \mathrm{~mm}$, which is consistent with earlier experiments in the same magnetic configuration but with inboard limiters instead of the divertors [13]. The poloidal phase velocity shown in the bottom panel reveals a sign change around $R=6.09 \mathrm{~m}$ (from positive $E_{r}$ outside of it to negative $E_{r}$ inside), indicating that the probe crossed the LCFS and entered the confined plasma. The plasma parameters at the LCFS are estimated as $T_{\mathrm{e}}=60 \mathrm{eV}, n=6 \cdot 10^{18} \mathrm{~m}^{-3}$ for program 20180829.51 and $T_{\mathrm{e}}=80 \mathrm{eV}, n=4 \cdot 10^{18} \mathrm{~m}^{-3}$ for program 20180829.52. The heat flux profiles in Figure 6 c) are calculated only up to this position since the definition of $q_{\|}=n c_{s} T_{\mathrm{e}}$ containing the sound velocity $c_{s}$ is not valid in the confined plasma.

The FOM limiter configuration (Figure 7), in contrast, was operated at higher densities and different heating power levels while the plasma duration was 

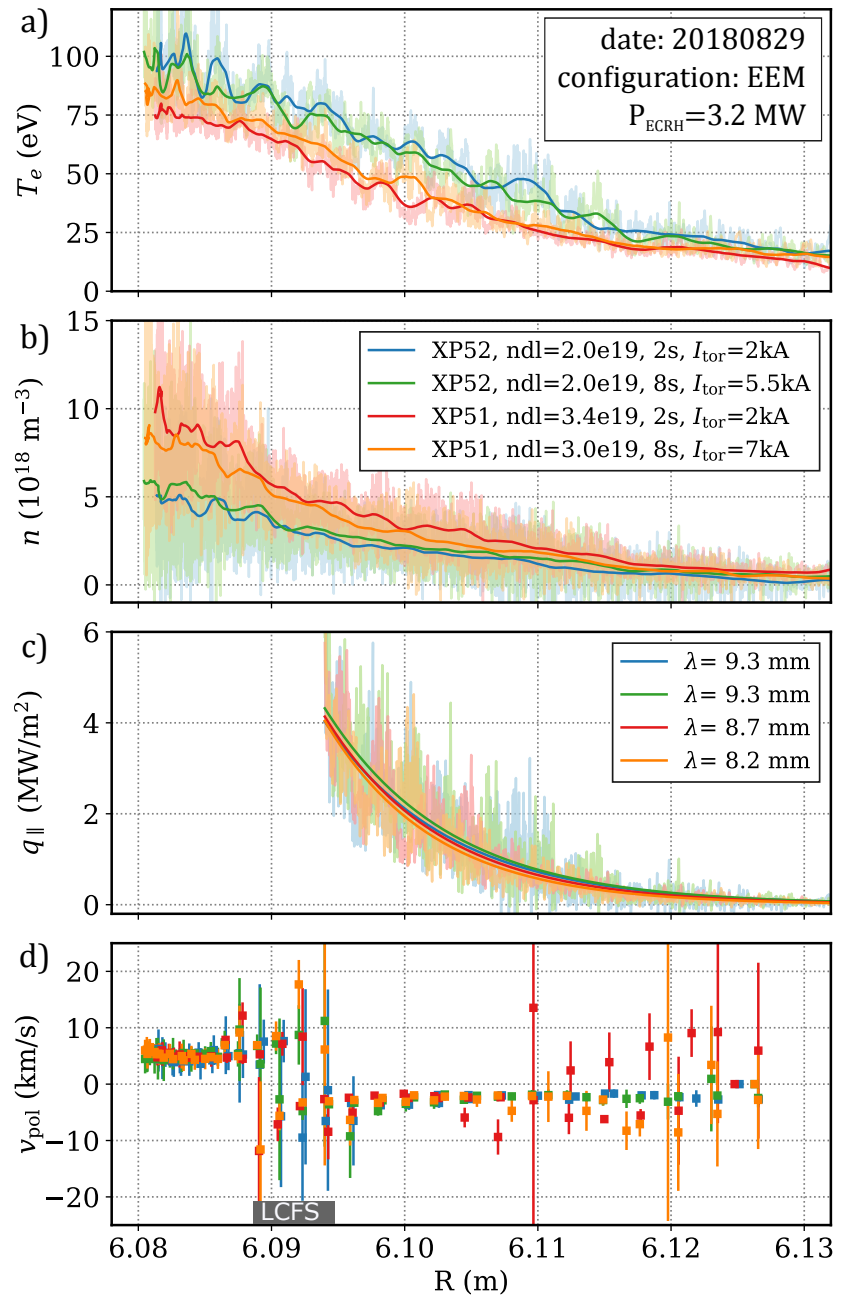

Figure 6. Radial profiles of electron temperature $T_{\mathrm{e}}$, plasma density $n$, parallel heat flux $q_{\|}$and poloidal phase velocity $v_{\text {pol }}$ in the EEM limiter configuration for two different plasma programs and two time instants within the programs, respectively. The parallel heat flux $q_{\|}$is only calculated up to the LCFS which we deduce from the region of sign flips in d), indicated by the black bar at the bottom. The error bars of $v_{\text {pol }}$ in d) represent the residuum from the linear fit according to the scheme presented in section 3. The sign is defined such that negative velocities indicate upward motion, i.e. correspond to a positive radial electric field.

shorter with 4-5s. Compared to the EEM case, the observed temperatures are smaller while the densities are higher. While the temperature profiles of the different plasma conditions are fairly similar with only a small dependence on $P_{E C R H}$, the density profiles show a clear dependence on $P_{E C R H}$ and $n_{d l}$. The heat flux profiles again have an approximately exponential shape with shorter decay lengths of 5-6 $\mathrm{mm}$. The phase velocity profiles depicted in the bottom panel indicate that the LCFS is located just inside $R=6.06 \mathrm{~m}$ in the programs with higher heating power / density (20180912.40/43/44). A close examination of the density profiles at the position of sign flip of the velocity
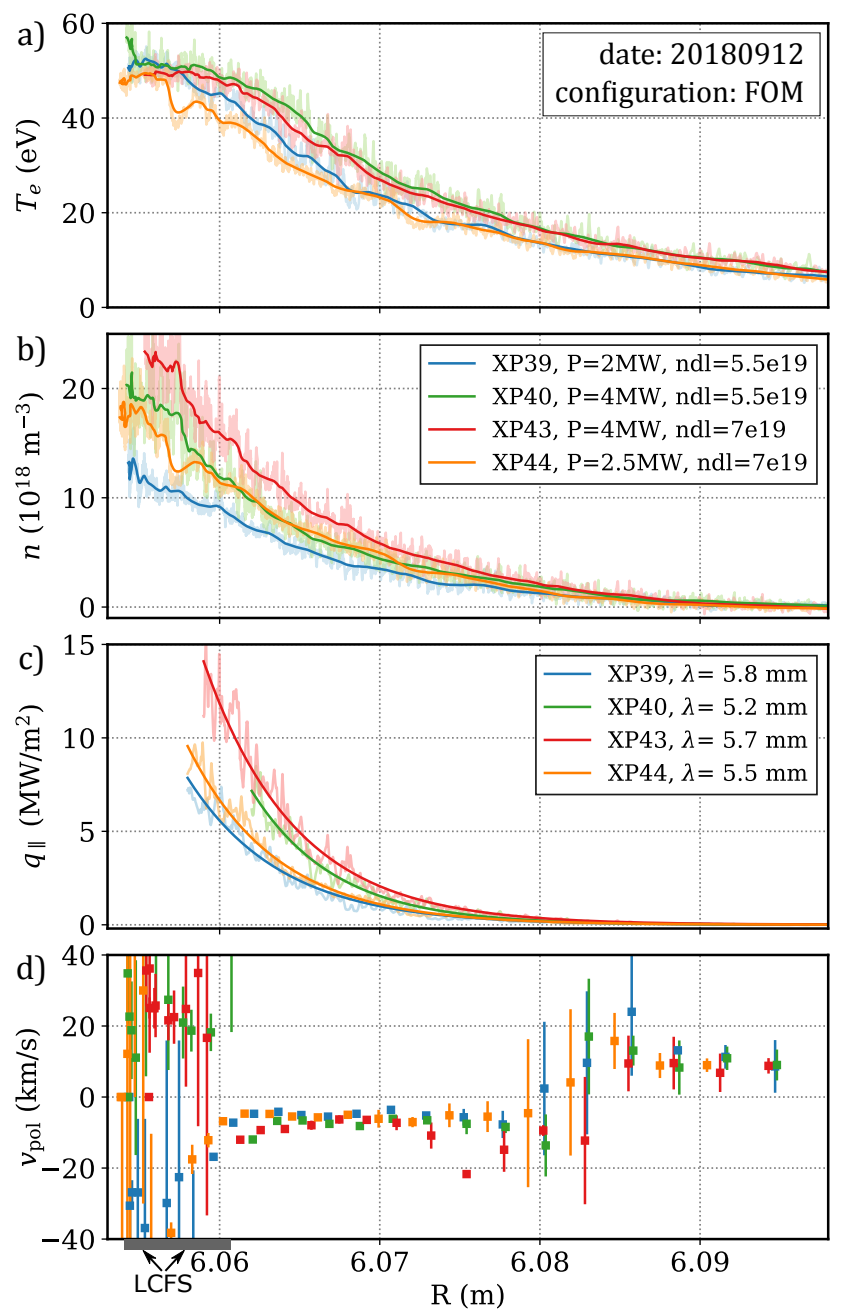

Figure 7. Radial profiles of electron temperature $T_{\mathrm{e}}$, plasma density $n$, parallel heat flux $q_{\|}$and poloidal phase velocity $v_{\text {pol }}$ in the FOM limiter configuration. The parallel heat flux $q_{\|}$is only calculated up to the LCFS which is estimated from the sign flip region in d), which is indicated the black bar at the bottom. Details on $v_{\text {pol }}$ data are given in the caption of Figure 6 .

reveals a particularly steep density gradient at this radial position. Extracting typical plasma parameters at the LCFS yields $T_{\mathrm{e}}=50 \mathrm{eV}$ and densities around $1.5-2 \cdot 10^{19} \mathrm{~m}^{-3}$. In the program with smallest performance (20180912.39), in contrast, no clear sign flip is observed and the corresponding density profile is not as steep. The apparently different LCFS position might indicate finite beta effects (such as Shafranov shift, iota change due to plasma currents) as the LCFS appears to move outwards for higher plasma pressure.

Finally, the observation of positive poloidal velocities in the far SOL for $R \geq 6.08 \mathrm{~m}$ is unexpected but will not be further discussed here since the associated error bars are quite large. However, we note that a similar phenomenon is also seen in the highest density case of the EEM configuration (Figure 6) and is sometimes also observed in the island divertor measurements which 

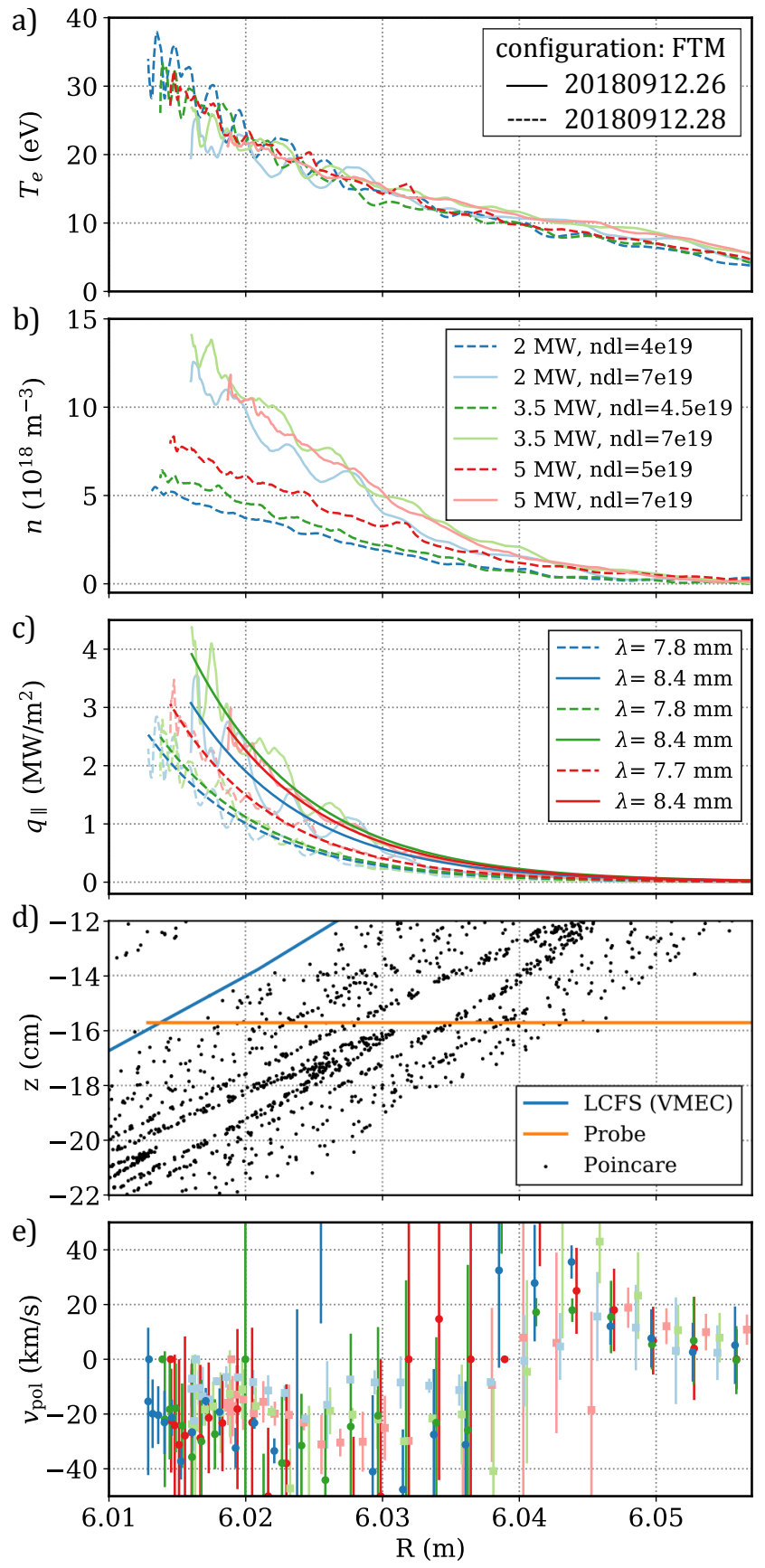

Figure 8. Radial profiles of electron temperature $T_{\mathrm{e}}$, plasma density $n$, parallel heat flux $q_{\|}$and poloidal phase velocity $v_{\text {pol }}$ in the high iota (FTM) configuration. The Poincare plot in the bottom panel indicates the probe path with respect to the magnetic topology. Note that the Poincare plot is distorted due to unequal axis scaling by design.

are presented in the following.

The high iota configuration features a single edge island which intersects each plasma cross sections at four different locations, see Figure $1 \mathrm{c})$ ). For the experiments presented in Figure 8, plasma programs of $8.5 \mathrm{~s}$ duration were conducted with a heating power step-down from $5 \mathrm{MW}$ over $3.5 \mathrm{MW}$ to $2 \mathrm{MW}$ where each phase lasted approximately $3 \mathrm{~s}$. The line integrated plasma density was kept constant at $7 \cdot 10^{19} \mathrm{~m}^{-2}$ in program 20180912.26, while in program 20180912.28 the density slightly decreased due to the power step down, see the labels in Figure 8. Towards the end of each heating power step, when the plasma is well equilibrated, a probe plunge into the plasma was performed.

The electron temperature profiles in the top panel of Figure 8 are very similar to each other and therefore appear stiff against changes in the central plasma conditions. The density, profiles, in contrast, show a strong dependence on the line integrated density, while an influence of the heating power is only seen in the lower density cases (dashed lines). The heat flux profiles can be well described by exponential decays with similar decay lengths around $8 \mathrm{~mm}$ in all data sets.

The close-up of the Poincare plot in the bottom panel of Figure 8 reveals that significant heat fluxes are only observed within the narrow magnetic island. From the ideal vacuum magnetic field calculations, the measurements should have been taken up to the LCFS in the lowest performance plasma and reach close to it in the other data sets. However, the $T_{\mathrm{e}}, n$, and $q_{\|}$values are rather small compared to the limiter configuration in Figure 7, and the poloidal phase velocity does not exhibit a sign flip towards positive values close to the plasma. All these observations indicate that the LCFS is located further radially inwards than expected from the ideal coil vacuum magnetic field calculations used for the Poincare plot calculation. In addition, the radial and poloidal position of the magnetic island is very sensitive to error fields [37, 38] or plasma currents [39] since the islands are formed by resonances. A further complication due to the presence of islands is the interpretation of the "poloidal" phase velocity since the inclination of the island flux surfaces changes along the probe path. Most drastically, in the center of the island a poloidal rotation of the island would be experienced as a radial flow by the probe array.

The low iota configuration (DBM) features six quite large edge islands which are surrounded by a broad region of stochastic field lines, see Figure $1 \mathrm{~b}$ ). The positions of the islands are such that the MPM crosses the SOL mostly through stochastic regions close to the $\mathrm{X}$-point and just barely grazes one island as can be seen in the close-up Poincare plot in the bottom panel of Figure 9. For the results presented in Figure 9 the role of heating power and line integrated density was studied by conducting multiple short plasma programs (4s duration) with constant plasma parameters in each program.

The temperature profiles in the top panel of Figure 9 show a little more diversity than in the previously discussed high iota case. Both a positive correlation with $P_{E C R H}$ and a small negative correlation with $n_{d l}$ can 

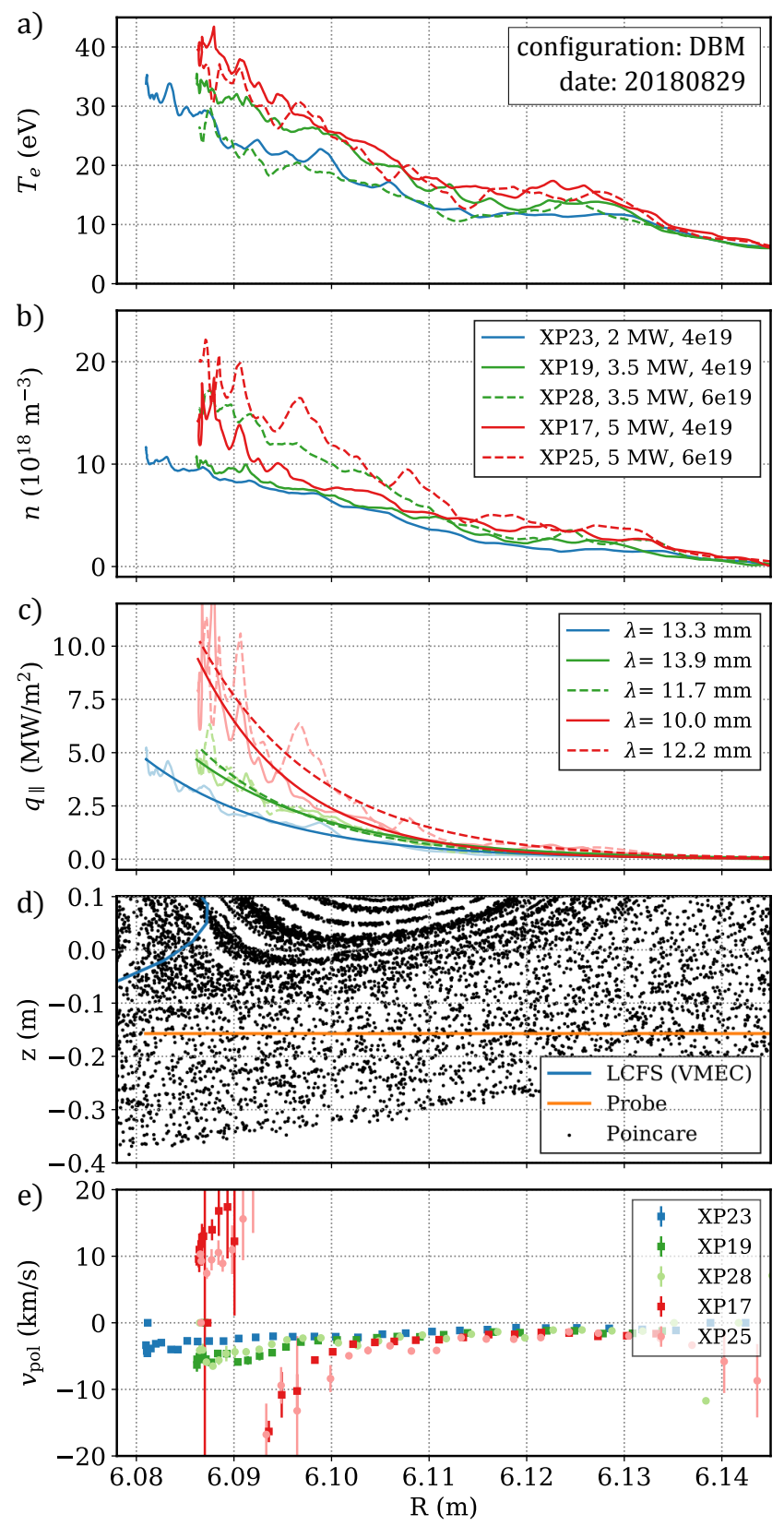

Figure 9. Radial profiles of electron temperature $T_{\mathrm{e}}$, plasma density $n$, parallel heat flux $q_{\|}$and poloidal phase velocity $v_{\text {pol }}$ in the low iota (DBM) configuration. The Poincare plot in the bottom panel indicates the probe path with respect to the magnetic topology. Note that the Poincare plot is distorted due to unequal axis scaling by design.

be observed. All temperature profiles, however, reveal a flat region between $R=6.11 \mathrm{~m}$ and $R=6.13 \mathrm{~m}$. From the Poincare plot, no particular feature of the magnetic topology can be associated with this plateau. The density profiles reveal a slight positive dependence on $P_{E C R H}$ and a significant dependence on $n_{d l}$. The heat flux profiles can again be approximated by exponential curves with decay lengths in the range of $10 \mathrm{~mm}$ to $14 \mathrm{~mm}$.
Table 3. Decay lengths from exponential fits of the parallel heat flux profiles taken by the MPM in different magnetic configurations (see Table 2).

\begin{tabular}{lc} 
Configuration & $\lambda_{q}(\mathrm{~mm})$ \\
\hline Low Iota (DBM) & $10-14$ \\
Low Iota Limiter (EEM) & $8-10$ \\
Standard (EJM) outside island & $4-9$ \\
Standard (EJM) inside island & $>20$ \\
High Iota Limiter (FOM) & $5-6$ \\
High Iota (FTM) & 8
\end{tabular}

Comparing the magnitudes of the depicted plasma parameters to the low iota limiter case (Figure 6), generally smaller temperatures are observed while the SOL densities remain roughly similar in relation to the respective line integrated densities. The poloidal phase velocities in the bottom panel indicate an increasingly positive radial electric field towards the plasma (see caption of Fig. 6 for explanations). Only in the highest heating power cases (red symbols), a sign flip is observed around $R=6.09 \mathrm{~m}$. The origin of this feature (which is consistently observed for various discharges at $5 \mathrm{MW}$ heating power, even in experiments in the low iota configuration with a reversed magnetic field direction) is not directly clear from the Poincare plot. Both a radial or poloidal movement of the island as well as a shift of the LCFS of the confined plasma due to finite plasma beta effects (e.g. Shafranov shift, impact of plasma currents on the edge rotational transform [39]) might be possible and will be subject to further investigation.

Finally, considering the four configurations investigated so far, it is interesting to note that the heat flux decay lengths show a correlation with the rotational transform as well as with the existence of a resonant island, see the compilation in Table 3. Comparing the limiter configurations, the SOL width is larger for smaller rotational transform, which agrees with basic connection lengths considerations and also follows typical tokamak scalings. As an example, the empirical scaling by Eich et al. [7] finds that the SOL width dominantly depends on the poloidal magnetic field and yields a heat flux decay length of $\approx 4 \mathrm{~mm}$ for typical W7-X parameters. In the island divertor configurations of similar rotational transforms, the decay lengths generally increase compared to the limiter cases, i.e. $\lambda_{D B M}>\lambda_{E E M}$ and $\lambda_{F T M}>\lambda_{F O M}$. A direct comparison of the DBM and FTM island divertor configurations is, however, not possible, since the probe is located at different poloidal positions with respect to the magnetic islands, see Fig. 1. The particularly interesting case of the standard configuration (EJM) will be presented and discussed in the following section. 
a)
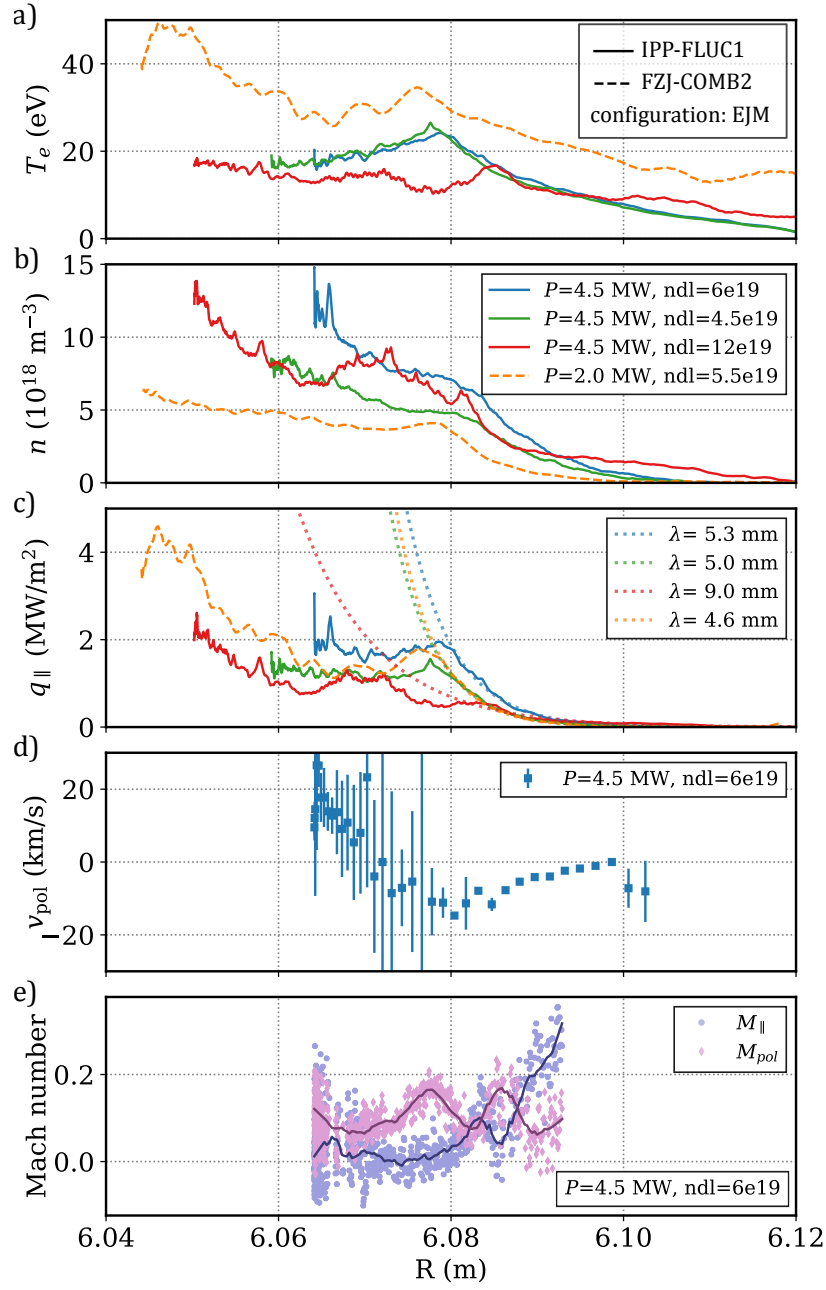

Figure 10. Radial profiles of electron temperature $T_{\mathrm{e}}$, plasma density $n$ and parallel heat flux $q_{\|}$in the magnetic standard configuration for different central plasma conditions (color coded) and two different probe heads (dashed/solid lines). The legend given in the b) applies to the color and line styles in a) and c) as well. In addition, the poloidal phase velocity $v_{p o l}$ and die parallel and poloidal Mach numbers are presented for one selected program in d) and e), respectively.

\section{SOL profiles and island dynamics in the magnetic standard configuration}

The magnetic standard configuration (EJM) is the most relevant configuration for edge plasma focused experiments on W7-X, but the interpretation of MPM probe measurements is quite challenging due to the complex magnetic topology illustrated in Figure 2. A choice of plasma profiles for different plasma scenarios in the standard configuration is presented in Figure 10. Starting with the electron temperature in the top panel, the MPM consistently observed nonmonotonous profiles with a local maximum around $R=$ $6.08 \mathrm{~m}$. This position coincides with a steep increase of the connection length from $\approx 10 \mathrm{~m}$ to $\approx 300 \mathrm{~m}$, see Figure 2. Surprisingly, the temperatures obtained with a triple probe on the FZJ-COMB2 probe head are generally signifcantly larger than the IPP-FLUC triple probe results, even at similar plasma conditions. This discrepancy might possibly be attributed to the observation that $T_{e}$ generally does not decrease to zero far from the plasma in the FZJ-COMB2 data [15] but needs further investigation.

Focussing on the temperature profiles taken with the IPP-FLUC1 probe (solid lines), we find that the SOL $T_{\mathrm{e}}$ profiles are remarkably reproducible in case of moderate variations of the plasma conditions (compare the blue and green line). Only at very high plasma densities with high levels of radiated power (a regime associated to detachment), a significant reduction of $T_{\mathrm{e}}$ is seen (red line). The plasma density in the SOL shows a more diverse picture and a non-trivial dependence on the line integrated density. In the moderate density range, $n_{S O L}$ appears to roughly scale with the line averaged density, while in the high density (red line) situations $n_{S O L}$ does not increase accordingly, indicating a detachment-like regime. As a common feature, the density profiles tend to flatten inside the position of the temperature peak.

The heat flux profiles in the standard configuration strongly deviate from exponential decay shapes seen in the other configurations. Only in the outer part of the profile, for $\approx R>6.08 \mathrm{~m}$, an exponential fall-off is visible. Correlating this position to Figure 2, one finds that this part of the profile corresponds to the region of short connection length. Fitting an exponential function to this part of the profile yields similar decay length to e.g. the limiter configurations or the tokamak scaling [7]. For $R<6.08 \mathrm{~m}$, heat flux profiles are several $\mathrm{cm}$ wide. This region corresponds to the inner side of the island chain with connection length of a few $100 \mathrm{~m}$. Such a broad heat flux profile is favorable for divertor operation as it distributes the heat flux over a larger area.

To illustrate further properties, poloidal phase velocities and Mach numbers are presented in Figure $10 \mathrm{~d}$ ) and e) for one of the programs in a)-c). First, the $v_{\text {pol }}$ profile reveals a sign change within the magnetic island, indicating a flip of $E_{r}$. The large error bars around the sign change might stem from the fact that at the center of the island the island flux surfaces do not align to the poloidal probe array any more. In the most extreme case (in the Poincare plot in Figure 2at $R \approx 6.075 \mathrm{~m}$ ), the probe array is oriented along the radial axis of the island instead of a poloidal island flux surface. The parallel Mach number decreases from about 0.3 to approximately zero when the probe moves from the far SOL into the island, which is qualitatively in agreement with EMC3-Eirene simulations [29]. The poloidal Mach number, in contrast, displays 

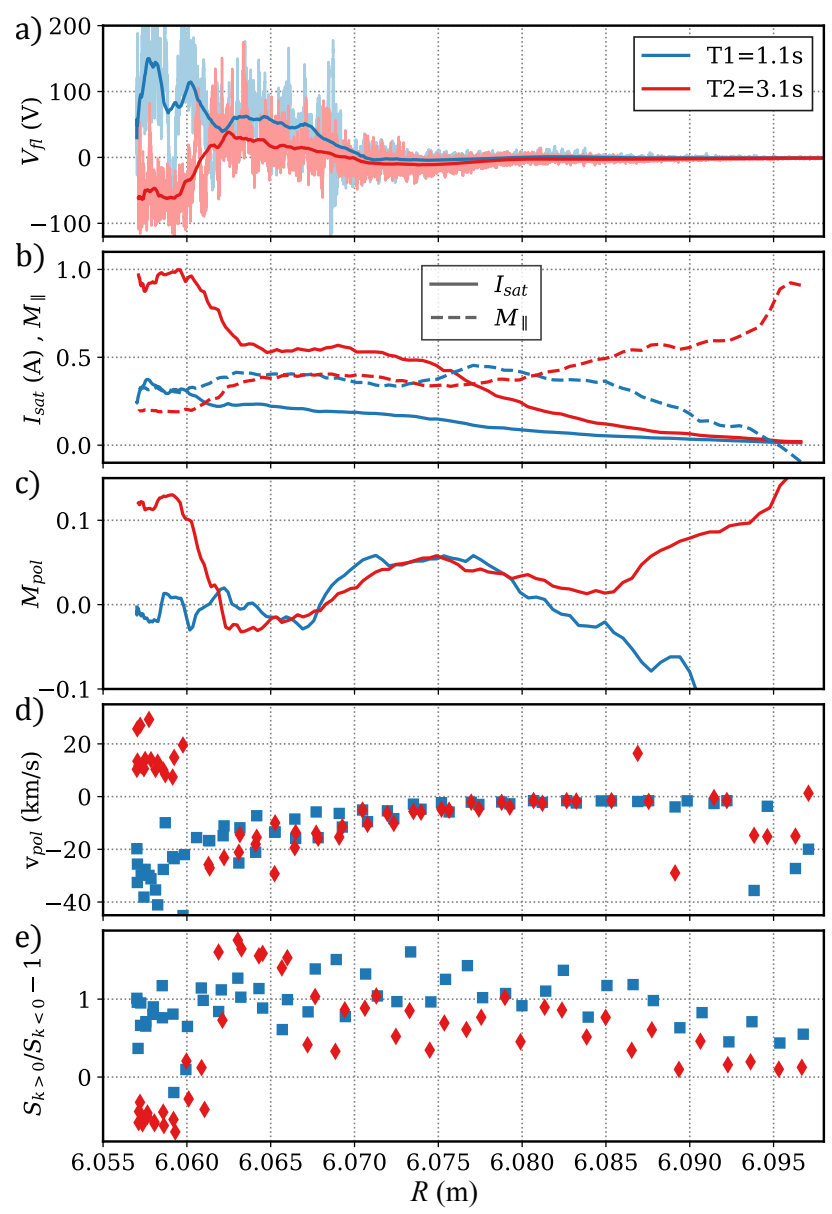

Figure 11. Radial profiles of floating potential (raw + smoothed), ion saturation current, parallel and poloidal Mach number, poloidal phase velocity, and ratio of power densities in positive and negative wave numbers in program 20171121.12 for two time instances. At $\mathrm{T} 1$, the key plasma parameters were $P_{\mathrm{ECRH}}=2.8 \mathrm{MW}$ and $n_{d l}=1.5 \cdot 10^{19} \mathrm{~m}^{-2}$. At T2, these had been increased to $P_{\mathrm{ECRH}}=5.2 \mathrm{MW}$ and $n_{d l}=4.5 \cdot 10^{19} \mathrm{~m}^{-2}$

a modulated behavior around $M_{p o l} \approx 0.1$ which is not yet understood in detail.

In the final part of this manuscript, we employ the diagnostic techniques presented above and in section 3 to demonstrate that the SOL island structure and dynamics is subject to plasma conditions and can change within a plasma program due to changes in heating power and core density. In program 20171121.12, a hydrogen plasma in the magnetic standard configuration started at $P_{\mathrm{ECRH}}=2.8 \mathrm{MW}$ and $n_{d l}=1.5 \cdot 10^{19} \mathrm{~m}^{-2}$ where it was probed by the MPM with the IPP-FLUC1 probe at $T 1=1.1 \mathrm{~s}$. Then, the heating power was almost doubled to $P_{\mathrm{ECRH}}=5.2 \mathrm{MW}$ and the density increased $3.5 \cdot 10^{19} \mathrm{~m}^{-2}$ over the course of $500 \mathrm{~ms}$. In this situation, a second probe measurement was taken at $T 2=3.1 \mathrm{~s}$.

The resulting probe data is presented in Figure 11. Since both $T_{\mathrm{e}}$ and $n$ profiles are unfortunately not available for this program (due to technical issues with triple and swept probes), we use floating potential and ion saturation current as measures for the SOL profiles. This approximation is justified by the relatively flat $T_{\mathrm{e}}$ profiles in the standard configuration, see Figure 10. In the following, all subplots of Figure 11 will be briefly discussed. We then make the case that the differences between $\mathrm{T} 1$ and $\mathrm{T} 2$ in the region $R<6.065 \mathrm{~m}$, which are visible in all depicted quantities, are related to each other and can be interpreted coherently.

The $V_{\text {fl }}$ profile in the first panel is drastically different in both measurements: At T1, it increases towards the plasma (on average, although with some strong excursions). At T2, in contrast, it drops to negative values for $R<6.06 \mathrm{~m}$. The ion saturation current profiles indicate that the SOL density correlates with the line integrated density, as the magnitude of the current roughly doubles in the island. Also, the flat density region around $R=6.07 \mathrm{~m}$ corresponds to the similar regions in Figure 10. The $M_{\|}$profiles are similar throughout most of the island but deviate close to the LCFS $(R<6.065 \mathrm{~m})$ and in the far SOL $(R>6.08 \mathrm{~m})$. The latter case can at least partly be attributed to uncertainties in the Mach probe analysis since the signal to noise ratio significantly worsens in the far SOL. The slightly smaller parallel Mach number in the higher density case at the innermost region might simply be explained by the higher collisionality, which impedes the plasma flow.

The poloidal Mach number profiles presented in the third panel are again similar in the region between $6.065 \mathrm{~m}$ and $6.08 \mathrm{~m}$, whereas a distinct difference is observed for $R<6.065 \mathrm{~m}$ : While $M_{\text {pol }} \approx 0$ at $\mathrm{T} 1$, it increases to $M_{\text {pol }} \gtrsim 0.1$ at T2. The $v_{\text {pol }}$ profiles in the fourth panel show similar behavior for both measurements in large parts of the profiles, but again a clear difference is seen for $R<6.065 \mathrm{~m}$. While $v_{\text {pol }}$ continues to decrease at T1 when going close to the LCFS (indicating positive electric fields of increasing magnitude), a sign flip is observed at $\mathrm{T} 2$, indicating a corresponding sign change of the radial electric field. This finding is supported by the bottom panel, which shows the normalized ratio of power densities from positive and negative wave numbers. These were obtained by first calculating $k$ spectra of plasma fluctuation data along the poloidal probe array. Then, to reduce the data complexity, the integrated power densities for all positive wave numbers $S_{k>0}$ and all negative wave numbers $S_{k<0}$ were determined. The normalized ratio of these two properties $S_{k>0} / S_{k<0}-1$, which is plotted in Figure $11 \mathrm{e}$ ), is then positive if the power density is higher for positive wave numbers and vice versa. Nicely agreeing with the previous $v_{\text {pol }}$ plot, we observe consistently more power in positive poloidal wave numbers (corresponding to negative $v_{\text {pol }}$ with the sign conventions 


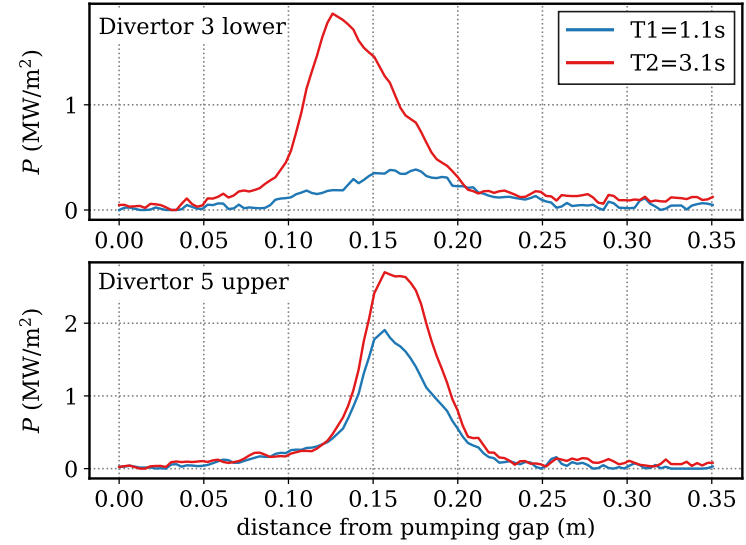

Figure 12. Heat flux profiles on the divertor modules which are magnetically connected to the MPM path at the time instances of the MPM plunges in program 20171121.12.

being made) in the $\mathrm{T} 1$ profiles and for most of the $\mathrm{T} 2$ profiles. Only in the innermost region, a reversal towards higher power densities in negative wave numbers is seen at time T2 since $S_{k>0} / S_{k<0}-1$ becomes negative.

Combining these observations leads to the conclusion that the radial electric field flips in the innermost part of the probed region at T2. Taking the floating potential as a rough proxy for the plasma potential (given that we know the $T_{\text {e }}$ profiles are quite flat), a sign flip of $E_{r}$ is expected by simply taking the gradient of the plasma potential. Since plasma fluctuations are considered to be $E \times B$ driven, the $E_{r}$ reversal therefore results in a corresponding sign flip of the poloidal phase velocity and the dominant poloidal wave numbers. The increase of the poloidal Mach number to significantly positive values (being defined as downwards motion) in this region further adds to this conclusion.

Looking at the bigger picture than local probe measurements, it is obvious to ask what happened in the plasma edge and why. From the probe measurements alone it is difficult to decide whether a) the island moved outwards between $\mathrm{T} 1$ and $\mathrm{T} 2$, and a deeper plunge at $\mathrm{T} 1$ would have recovered the same results, or, b) a qualitative change of transport processes in the edge occurred. In both cases the underlying actuator is not easily determined, as plasma beta effects are not expected to be too important $(\beta<1 \%)$ and the toroidal bootstrap current is small $\left(I_{\text {tor }}(T 1)=1 \mathrm{kA}\right.$, $\left.I_{t o r}(T 2)=2.5 \mathrm{kA}\right)$. Field line tracing calculations incorporating such plasma currents do not reveal significant effects on the position or size of the magnetic island but might hint at a change in the connection length distribution [15].

To investigate the corresponding downstream response, the poloidal heat load profiles [40] on the two divertor modules that are magnetically connected to the MPM are shown in Figure 12. At T1, the heat load distribution is quite asymmetric, as the upper divertor in module 5 receives a four times higher heat load than the lower divertor in module 3 . After the heating and density increase, at $\mathrm{T} 2$, the upper divertor in module 5 reveals only a moderate increase of the heat flux magnitude with the same spatial distribution as at T1. At the lower divertor in module 3 , in contrast, the heat flux peak quadruples while the overall heat flux profile moves towards the pumping gap. A shift in this direction implies an outwards movement of the island at the position of the MPM, which is consistent with the observations in Figure 11. The origin of this shift and the disparity between both investigated divertors remains yet to be understood.

\section{Summary and conclusion}

The W7-X SOL has been investigated using reciprocating electric probes mounted on the Multi-Purpose Manipulator. Radial profiles of electron temperature, density, parallel heat flux, poloidal phase velocity, as well as parallel and poloidal Mach number have been obtained using a novel probe head (IPP-FLUC1) in three major island divertor configurations and two limiter scenarios without edge islands. We find that the SOL plasma profiles approximately resemble exponential decays with characteristic decay lengths comparable to tokamak scalings [7] in the following situations:

- islands are very narrow (high iota, FTM)

- islands are not crossed by the MPM (low iota, DBM)

- no edge islands at all (limiter, EEM/FOM)

- outside the islands' long connection length region (standard, EJM)

The SOL across wide magnetic islands is, in contrast, very wide. There, we typically observe flat temperature and shallow density profiles across the long connection length region of the magnetic islands. Inside the island, the radial electric field and associated $E \times B$ dynamics can change their sign, indicating a confined region within the island and a rotation of the entire island. The position of this sign change can be affected by varying the central plasma heating and fuelling.

\section{Acknowledgments}

This work has been carried out within the framework of the EUROfusion Consortium and has received funding from the Euratom research and training programme 2014-2018 and 2019-2020 under grant agreement number 633053. The views and opinions 
expressed herein do not necessarily reflect those of the European Commission.

[1] Grigull P, McCormick K, Baldzuhn J, Burhenn R, Brakel R, Ehmler H, Feng Y, Gadelmeier F, Giannone L, Hartmann D, Hildebrandt D, Hirsch M, Jaenicke R, Kisslinger J, Knauer J, König R, Kühner G, Laqua H, Naujoks D, Niedermeyer H, Ramasubramanian N, Rust N, Sardei F, Wagner F, Weller A, Wenzel U and the W7AS Team 2001 Plasma Physics and Controlled Fusion 43 A175 URL http://stacks.iop.org/0741-3335/43/i= $12 \mathrm{~A} / \mathrm{a}=313$

[2] König R, Grigull P, McCormick K, Feng Y, Kisslinger J, Komori A, Masuzaki S, Matsuoka K, Obiki T, Ohyabu N, Renner H, Sardei F, Wagner F and Werner A 2002 Plasma Physics and Controlled Fusion 442365 URL http://stacks.iop.org/0741-3335/44/i=11/a=306

[3] Strumberger E 1996 Nuclear Fusion 36891 URL http: //stacks.iop.org/0029-5515/36/i=7/a=I06

[4] Wolf R, Ali A, Alonso A, Baldzuhn J, Beidler C, Beurskens M, Biedermann C, Bosch H S, Bozhenkov S, Brakel R, Dinklage A, Feng Y, Fuchert G, Geiger J, Grulke O, Helander P, Hirsch M, Höfel U, Jakubowski M, Knauer J, Kocsis G, König R, Kornejew P, Krämer-Flecken A, Krychowiak M, Landreman M, Langenberg A, Laqua H, Lazerson S, Maaßberg H, Marsen S, Marushchenko M, Moseev D, Niemann H, Pablant N, Pasch E, Rahbarnia $\mathrm{K}$, Schlisio G, Stange T, Pedersen T S, Svensson J, Szepesi T, Mora H T, Turkin Y, Wauters T, Weir G, Wenzel U, Windisch T, Wurden G, Zhang D, Abramovic I, Äkäslompolo S, Aleynikov P, Aleynikova K, Alzbutas R, Anda G, Andreeva T, Ascasibar E, Assmann J, Baek S G, Banduch M, Barbui T, Barlak M, Baumann K, Behr W, Benndorf A, Bertuch O, Biel W, Birus D, Blackwell B, Blanco E, Blatzheim M, Bluhm T, Böckenhoff D, Bolgert P, Borchardt M, Borsuk V, Boscary J, Böttger L G, Brand H, Brandt C, Bräuer T, Braune H, Brezinsek S, Brunner K J, Brünner B, Burhenn R, Buttenschön B, Bykov V, Calvo I, Cannas B, Cappa A, Carls A, Carraro L, Carvalho B, Castejon F, Charl A, Chernyshev F, Cianciosa M, Citarella R, Ciupiński, Claps G, Cole M, Cole M, Cordella F, Cseh G, Czarnecka A, Czermak A, Czerski K, Czerwinski M, Czymek G, da Molin A, da Silva A, Dammertz G, Danielson J, de la Pena A, Degenkolbe S, Denner P, Dhard D, Dostal M, Drevlak M, Drewelow P, Drews P, Dudek A, Dundulis G, Durodie F, van Eeten P, Effenberg F, Ehrke G, Endler M, Ennis D, Erckmann E, Esteban H, Estrada T, Fahrenkamp N, Feist J H, Fellinger J, Fernandes H, Fietz W, Figacz W, Fontdecaba J, Ford O, Fornal T, Frerichs H, Freund A, Führer M, Funaba T, Galkowski A, Gantenbein G, Gao Y, Regaña J G, Garcia-Munoz M, Gates D, Gawlik G, Geiger B, Giannella V, Gierse N, Gogoleva A, Goncalves B, Goriaev A, Gradic D, Grahl M, Green J, Grosman A, Grote H, Gruca M, Guerard C, Haiduk L, Han X, Harberts F, Harris J, Hartfuß H J, Hartmann D, Hathiramani D, Hein B, Heinemann B, Heitzenroeder P, Henneberg S, Hennig C, Sanchez J H, Hidalgo C, Hölbe H, Hollfeld K, Hölting A, Höschen D, Houry M, Howard J, Huang X, Huber M, Huber V, Hunger H, Ida $\mathrm{K}$, Ilkei $\mathrm{T}$, Illy $\mathrm{S}$, Israeli $\mathrm{B}$, Ivanov A, Jablonski $\mathrm{S}$, Jagielski J, Jelonnek J, Jenzsch H, Junghans P, Kacmarczyk J, Kaliatka T, Kallmeyer J P, Kamionka U, Karalevicius R, Kasahara H, Kasparek W, Kenmochi N, Keunecke M, Khilchenko A, Kinna D, Kleiber R, Klinger T, Knaup M, Kobarg T, Köchl F, Kolesnichenko Y, Könies A, Köppen M, Koshurinov J, Koslowski R, Köster F, Koziol R, Krämer M, Krampitz R, Kraszewsk P, Krawczyk N, Kremeyer T, Krings T, Krom J, Krzesinski G, Ksiazek I, Kubkowska M, Kühner G, Kurki-Suonio $\mathrm{T}$, Kwak S, Lang R, Langish S, Laqua H, Laube R,
Lechte C, Lennartz M, Leonhardt W, Lewerentz L, Liang Y, Linsmeier C, Liu S, Lobsien J F, Loesser D, Cisquella J L, Lore J, Lorenz A, Losert M, Lubyako L, Lücke A, Lumsdaine A, Lutsenko V, Majano-Brown J, Marchuk O, Mardenfeld M, Marek P, Massidda S, Masuzaki S, Maurer D, McCarthy K, McNeely P, Meier A, Mellein D, Mendelevitch B, Mertens P, Mikkelsen D, Mishchenko O, Missal B, Mittelstaedt J, Mizuuchi $\mathrm{T}$, Mollen A, Moncada V, Mönnich T, Morizaki T, Munk R, Murakami S, Musielok F, Náfrádi G, Nagel M, Naujoks D, Neilson H, Neubauer O, Neuner U, Ngo T, Nocentini R, Nührenberg C, Nührenberg J, Obermayer S, Offermanns G, Ogawa K, Ongena J, Oosterbeek J, Orozco G, Otte M, Rodriguez L P, Pan W, Panadero N, Alvarez N P, Panin A, Papenfuß D, Paqay S, Pavone A, Pawelec E, Pelka G, Peng X, Perseo V, Peterson B, Pieper A, Pilopp D, Pingel S, Pisano F, Plaum B, Plunk G, Povilaitis M, Preinhaelter J, Proll J, Puiatti M E, Sitjes A P, Purps F, Rack M, Récsei S, Reiman A, Reiter D, Remppel F, Renard S, Riedl R, Riemann J, Rimkevicius S, Riße K, Rodatos A, Röhlinger $\mathrm{H}$, Romé M, Rong P, Roscher H J, Roth B, Rudischhauser L, Rummel K, Rummel T, Runov A, Rust N, Ryc L, Ryosuke S, Sakamoto R, Samartsev A, Sanchez M, Sano F, Satake S, Satheeswaran G, Schacht J, Schauer F, Scherer T, Schlaich A, Schlüter K H, Schmitt J, Schmitz H, Schmitz O, Schmuck S, Schneider M, Schneider W, Scholz M, Scholz P, Schrittwieser R, Schröder M, Schröder T, Schroeder R, Schumacher H, Schweer B, Shanahan B, Shikhovtsev I, Sibilia M, Sinha P, Sipliä S, Skodzik J, Slaby C, Smith H, Spiess W, Spong D, Spring A, Stadler R, Standley B, Stephey L, Stoneking M, Stridde U, Sulek Z, Surko C, Suzuki Y, Szabó V, Szabolics T, Szökefalvi-Nagy Z, Tamura N, Terra A, Terry J, Thomas J, Thomsen H, Thumm M, von Thun C, Timmermann D, Titus P, Toi K, Travere J, Traverso P, Tretter J, Tsuchiya H, Tsujimura T, Tulipán S, Turnyanskiy M, Unterberg B, Urban J, Urbonavicius E, Vakulchyk I, Valet S, van Millingen B, Vela L, Velasco $\mathrm{J}$ L, Vergote M, Vervier M, Vianello N, Viebke H, Vilbrandt R, Vorkörper A, Wadle S, Wagner F, Wang E, Wang N, Warmer F, Wegener L, Weggen J, Wei Y, Wendorf J, Werner A, Wiegel B, Wilde F, Winkler E, Winters V, Wolf S, Wolowski J, Wright A, Xanthopoulos P, Yamada H, Yamada I, Yasuh 2017 Nuclear Fusion 57102020 URL http://stacks.iop.org/0029-5515/57/ $i=10 / a=102020$

[5] Sunn Pedersen T, Dinklage A, Turkin Y, Wolf R, Bozhenkov S, Geiger J, Fuchert G, Bosch H S, Rahbarnia $\mathrm{K}$, Thomsen $\mathrm{H}$, Neuner $\mathrm{U}$, Klinger $\mathrm{T}$, Langenberg A, Trimiño Mora H, Kornejew P, Knauer J, Hirsch $\mathrm{M}$ and Pablant N 2017 Physics of Plasmas $\mathbf{2 4}$ 055503 (Preprint https://doi.org/10.1063/1.4983629) URL https://doi.org/10.1063/1.4983629

[6] Klinger T and Team W X 2018 Overview of first wendelstein 7 -x high-performance operation with island divertor $27 \mathrm{th}$ IAEA FEC

[7] Eich T, Leonard A, Pitts R, Fundamenski W, Goldston R, Gray T, Herrmann A, Kirk A, Kallenbach A, Kardaun O, Kukushkin A, LaBombard B, Maingi R, Makowski M, Scarabosio A, Sieglin B, Terry J, Thornton A, Team A U and Contributors J E 2013 Nuclear Fusion 53 093031 URL http://stacks.iop.org/0029-5515/53/i= $9 / a=093031$

[8] Stangeby P and McCracken G 1990 Nuclear Fusion 301225 URL http://stacks.iop.org/0029-5515/30/i=7/a=005

[9] Bleuel J, Endler M, Niedermeyer H, Schubert M, Thomsen H and Team T W A 2002 New Journal of Physics 438 URL http://stacks.iop.org/1367-2630/4/i=1/a=338

[10] Müller H, Adamek J, Cavazzana R, Conway G, Fuchs C, 
Gunn J, Herrmann A, Horaček J, Ionita C, Kallenbach A, Kočan M, Maraschek M, Maszl C, Mehlmann F, Nold B, Peterka M, Rohde V, Schweinzer J, Schrittwieser $\mathrm{R}$, Vianello N, Wolfrum E, Zuin $\mathrm{M}$ and the ASDEX Upgrade Team 2011 Nuclear Fusion 51073023 URL http://stacks.iop.org/0029-5515/51/i=7/a=073023

[11] Silva C, Arnoux G, Devaux S, Frigione D, Groth M, Horacek J, Lomas P, Marsen S, Matthews G, Meneses L, Pitts R and Contributors J E 2014 Nuclear Fusion 54 083022 URL http://stacks.iop.org/0029-5515/54/ $i=8 / a=083022$

[12] Nicolai D, Borsuk V, Drews P, Grulke O, Hollfeld K, Krings T, Liang Y, Linsmeier C, Neubauer O, Satheeswaran G, Schweer B and Offermanns G 2017 Fusion Engineering and Design 123960 - 964 ISSN 0920-3796 proceedings of the 29th Symposium on Fusion Technology (SOFT29) Prague, Czech Republic, September 5-9, 2016 URL http://www.sciencedirect.com/science/article/ pii/S0920379617302168

[13] Drews P, Liang Y, Liu S, Krämer-Flecken A, Neubauer O, Geiger J, Rack M, Nicolai D, Grulke O, Killer C, Wang N, Charl A, Schweer B, Denner P, Henkel M, Gao Y, Hollfeld K, Satheeswaran G, Sandri N, Höschen D and Team T W X 2017 Nuclear Fusion 57126020 URL http: //stacks.iop.org/0029-5515/57/i=12/a=126020

[14] Liu S, Liang Y, Drews P, Krämer-Flecken A, Han X, Nicolai D, Satheeswaran G, Wang N, Cai J, Charl A, Cosfeld J, Fuchert G, Gao Y, Geiger J, Grulke O, Henkel M, Hirsch M, Hoefel U, Hollfeld K, Höschen D, Killer C, Knieps A, König R, Neubauer O, Pasch E, Rahbarnia K, Rack M, Sandri N, Sereda S, Schweer B, Wang E, Wei Y, Weir G, Windisch T and Team W X 2018 Nuclear Fusion 58046002 URL http://stacks.iop.org/0029-5515/58/ $i=4 / a=046002$

[15] Drews P, Killer C, Cosfeld J, Knieps A, Brezinsek S, Jakubowski M, Brandt C, Bozhenkov S, Dinklage A, Cai J, Endler M, Hammond K, Henkel M, Gao Y, Geiger J, Grulke $\mathrm{O}$, Höschen $\mathrm{D}$, König R, KrämerFlecken A, Liang Y, Li Y, Liu S, Niemann H, Nicolai D, Neubauer O, Neuner U, Rack M, Rahbarnia K, Rudischhauser L, Sandri N, Satheeswaran G, Schilling S, Thomsen H, Windisch T and Sereda S 2019 Nuclear Materials and Energy 19179 - 183 ISSN 2352-1791 URL http://www.sciencedirect.com/science/article/ pii/S2352179118301108

[16] Liu S, Liang Y, Drews P, Killer C, Knieps A, Xu G, Wang H, Yan N, Han X, Höschen D, Kraemer-Flecken A, Nicolai D, Satheeswaran G, Hammond K, Cai J, Charl A, Cosfeld J, Fuchert G, Gao Y, Geiger J, Grulke O, Henkel M, Hirsch M, Höfel U, König R, Li Y, Neubauer O, Pasch E, Rahbarnia K, Rack M, Sandri N, Sereda S, Schweer B, Wang E, Xu S and Gao X 2019 Nuclear Fusion URL http://iopscience.iop.org/10.1088/1741-4326/ab0d29

[17] Cai J, Liang Y, Killer C, Liu S, Hiller A, Knieps A, Schweer B, Höschen D, Nicolai D, Offermanns G, Satheeswaran G, Henkel M, Hollfeld K, Grulke O, Drews P, Krings $\mathrm{T}$ and Li Y 2019 Review of Scientific Instruments 90 033502 (Preprint https://doi.org/10.1063/1.5054279) URL https://doi.org/10.1063/1.5054279

[18] Henkel M, Höschen D, Liang Y, Li Y, Liu S, Nicolai D, Sandri N, Satheeswaran G, Yan N, Zhang H X and the EAST team 2018 Plasma Science and Technology 20054001 URL http://stacks.iop.org/1009-0630/20/ $i=5 / a=054001$

[19] Agostinetti P, Spolaore M, Brombin M, Cervaro V, Franchin L, Grulke O, Killer C, Martines E, Moresco M, Peruzzo S, Vianello N and Visentin M 2018 IEEE Transactions on Plasma Science 46 1306-1311 ISSN 0093-3813

[20] Ogawa K, Isobe M, Osakabe M, Bozhenkov S, Äkäslompolo
S, Killer C and Wolf R 2018 Development of faraday-cupbased fast ion loss detector in wendelstein 7-x 45th EPS Conference on Plasma Physics

[21] Wegner T, Geiger B, Kunkel F, Burhenn R, Schröder T, Biedermann C, Buttenschön B, Cseh G, Drews P, Grulke O, Hollfeld K, Killer C, Kocsis G, Krings T, Langenberg A, Marchuk O, Neuner U, Nicolai D, Offermanns G, Pablant N A, Rahbarnia K, Satheeswaran G, Schilling J, Schweer B, Szepesi T and Thomsen H 2018 Review of Scientific Instruments 89073505 (Preprint https: //doi.org/10.1063/1.5037543) URL https://doi.org/ $10.1063 / 1.5037543$

[22] Nagy A, Bortolon A, Gates D, Gilson E, Killer C, Klinger $\mathrm{T}$, Lunsford R, Maingi R, Mansfield D, Mauzey D, Nazikian R, Roquemore $\mathrm{L}$ and Wolfe $\mathrm{E}$ 2019 Fusion Engineering and Design ISSN 0920-3796 URL http://www.sciencedirect.com/science/article/ pii/S0920379618308573

[23] Satheeswaran G, Hollfeld K, Drews P, Nicolai D, Neubauer O, Schweer B and Grulke O 2017 Fusion Engineering and Design 123699 - 702 ISSN 0920-3796 proceedings of the 29th Symposium on Fusion Technology (SOFT29) Prague, Czech Republic, September 5-9, 2016 URL http://www.sciencedirect.com/science/article/ pii/S092037961730683X

[24] Smick N and LaBombard B 2009 Review of Scientific Instruments $\mathbf{8 0} 023502$ (Preprint https: //doi.org/10.1063/1.3069290) URL https://doi.org/ $10.1063 / 1.3069290$

[25] Smick N, LaBombard B and Hutchinson I 2013 Nuclear Fusion 53023001 URL http://stacks.iop.org/0029$5515 / 53 / i=2 / a=023001$

[26] Goodfellow www.goodfellow.com High purity boron nitride

[27] Chen S and Sekiguchi T 1965 Journal of Applied Physics 36 2363-2375 (Preprint https://doi.org/10.1063/ 1.1714492) URL https://doi.org/10.1063/1.1714492

[28] Hutchinson I H 2002 Principles of Plasma Diagnostics 2nd ed (Cambridge University Press)

[29] Effenberg F, Feng Y, Schmitz O, Frerichs H, Bozhenkov S, Hölbe H, König R, Krychowiak M, Pedersen T S, Reiter D, Stephey L and Team W X 2017 Nuclear Fusion 57036021 URL http://stacks.iop.org/0029-5515/57/ $i=3 / a=036021$

[30] Ballinger S, Terry J, Baek S, Tang K, von Stechow A, Killer C, Nicolai D, Satheeswaran G, Drews P and Grulke O 2018 Nuclear Materials and Energy 17269 - 273 ISSN 2352-1791 URL http://www.sciencedirect.com/ science/article/pii/S2352179118301121

[31] Kraemer-Flecken A, Han X, Windisch T, Cosfeld J, Drews P, Fuchert G, Geiger J, Grulke O, Killer C, Knieps A, Liang Y, Liu S and Rack M 2019 Plasma Physics and Controlled Fusion URL http://iopscience.iop.org/ 10.1088/1361-6587/ab0624

[32] Lin H, Li G X, Bengtson R D, Ritz C P and Tsui H Y W 1992 Review of Scientific Instruments 63 4611-4613 (Preprint https://doi.org/10.1063/1.1143684) URL https://doi.org/10.1063/1.1143684

[33] Theiler C, Furno I, Kuenlin A, Marmillod P and Fasoli A 2011 Review of Scientific Instruments 82 013504 (Preprint https://doi.org/10.1063/1.3516045) URL https://doi.org/10.1063/1.3516045

[34] Drews P, Niemann H, Cosfeld J, Gao Y, Geiger J, Grulke O, Henkel M, Höschen D, Hollfeld K, Killer C, KrämerFlecken A, Liang Y, Liu S, Nicolai D, Neubauer O, Rack M, Schweer B, Satheeswaran G, Rudischhauser L, Sandri $\mathrm{N}$, Wang N and the W7-X Team 2018 Plasma Science and Technology 20054003 URL http://stacks.iop.org/ $1009-0630 / 20 / i=5 / a=054003$

[35] Goldston R 2012 Nuclear Fusion 52013009 URL http: //stacks.iop.org/0029-5515/52/i=1/a=013009 
[36] Horacek J, Pitts R A, Adamek J, Arnoux G, Bak J G, Brezinsek S, Dimitrova M, Goldston R J, Gunn J P, Havlicek J, Hong S H, Janky F, LaBombard B, Marsen S, Maddaluno G, Nie L, Pericoli V, Popov T, Panek R, Rudakov D, Seidl J, Seo D S, Shimada M, Silva C, Stangeby P C, Viola B, Vondracek P, Wang H, Xu G S and and Y X 2016 Plasma Physics and Controlled Fusion 58074005 URL https://doi.org/ $10.1088 \% 2 \mathrm{~F} 0741-3335 \% 2 \mathrm{~F} 58 \% 2 \mathrm{~F} 7 \% 2 \mathrm{~F} 074005$

[37] Bozhenkov S, Lazerson S, Otte M, Gates D, Pedersen T S and Wolf R 2016 Nuclear Fusion 56076002 URL http://stacks.iop.org/0029-5515/56/i=7/a=076002

[38] Lazerson S A, Otte M, Jakubowski M, Israeli B, Wurden G A, Wenzel U, Andreeva T, Bozhenkov S, Biedermann C, Kocsis G, Szepesi T, Geiger J, Pedersen T S, Gates D and Team T W X 2017 Nuclear Fusion 57046026 URL http://stacks.iop.org/0029-5515/57/i=4/a=046026

[39] Geiger J, Beidler C, Drevlak M, Maaßberg H, Nührenberg C, Suzuki Y and Turkin Y 2010 Contributions to Plasma Physics 50 770-774 ISSN 1521-3986 URL https:// doi.org/10.1002/ctpp. 200900028

[40] Gao Y, Jakubowski M, Drewelow P, Pisano F, Sitjes A P, Niemann H, Ali A and Cannas B 2019 Nuclear Fusion URL http://iopscience.iop.org/10.1088/1741$4326 / \mathrm{abOf} 49$ 